WSRC-STI-2008-00358, Rev. 0

\title{
Tritium Barrier Materials and Separation Systems for the NGNP
}

Steven R. Sherman

Thad M. Adams

August 2008

$\begin{aligned} & \text { Washington Savannah River Company } \\ & \text { Savannah River National Laboratory } \\ & \text { Aiken, SC } 29808\end{aligned}$
$\begin{aligned} & \text { Prepared for the NGNP Project under MPO } \\ & \text { 00072051, Battelle Energy Alliance }\end{aligned}$




\section{DISCLAIMER}

This document was prepared by Washington Savannah River Company (WSRC)
Contract No. DE-AC09-96SR18500 with the United States of America, represented by
the Department of Energy. Neither the U.S. Government nor WSRC, nor any of their
employees makes any warranty, expressed or implied, or assumes any legal liability or
responsibility for any apparatus, product, or process disclosed, or represents that its use
would not infringe on privately owned rights. References herein to any commercial
products, process, or service by trade name, trade mark, manufacturer, or otherwise does
not necessarily constitute its endorsement, recommendation, or favoring by the U.S.
Government or WSRC. The views and opinions of the authors herein do not necessarily
state or reflect those of the U.S. Government or WSRC.




\begin{abstract}
Contamination of downstream hydrogen production plants or other users of high-temperature heat is a concern of the Next Generation Nuclear Plant (NGNP) Project. Due to the high operating temperatures of the NGNP $\left(850-900^{\circ} \mathrm{C}\right.$ outlet temperature), tritium produced in the nuclear reactor can permeate through heat exchangers to reach the hydrogen production plant, where it can become incorporated into process chemicals or the hydrogen product. The concentration limit for tritium in the hydrogen product has not been established, but it is expected that any future limit on tritium concentration will be no higher than the air and water effluent limits established by the NRC and the EPA. A literature survey of tritium permeation barriers, capture systems, and mitigation measures is presented and technologies are identified that may reduce the movement of tritium to the downstream plant. Among tritium permeation barriers, oxide layers produced in-situ may provide the most suitable barriers, though it may be possible to use aluminized surfaces also. For tritium capture systems, the use of getters is recommended, and hightemperature hydride forming materials such as $\mathrm{Ti}, \mathrm{Zr}$, and $\mathrm{Y}$ are suggested. Tritium may also be converted to HTO in order to capture it on molecular sieves or getter materials. Counter-flow of hydrogen may reduce the flux of tritium through heat exchangers. Recommendations for research and development work are provided.
\end{abstract}




\section{TABLE OF CONTENTS}

ABSTRACT

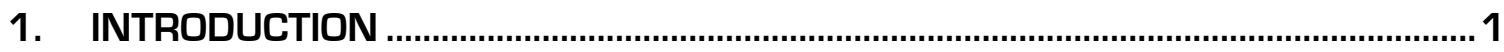

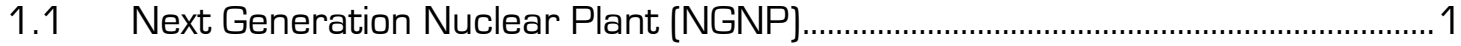

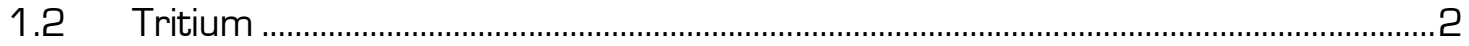

1.2.1 Tritium Generation ................................................................................................

1.2.2 Regulatory Limits …………………………………………………………….

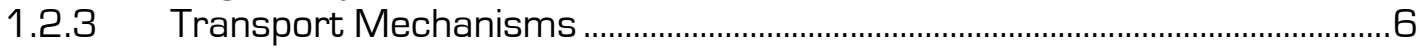

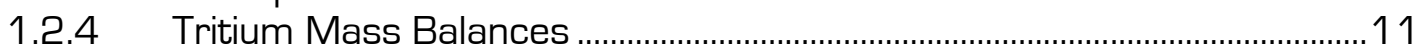

1.3 Barriers, Separation Systems, and Mitigation Measures.....................................15

2. TRITIUM BARRIERS................................................................................................ 17

2.1 Externally Applied Barriers ………………………………………………………....20

2.1.1 Alumina ………………………………………………………………………...20

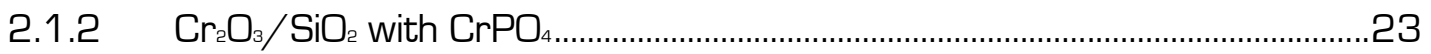

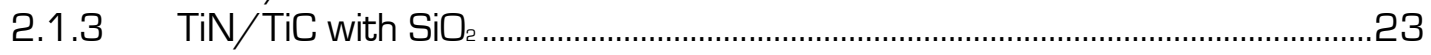

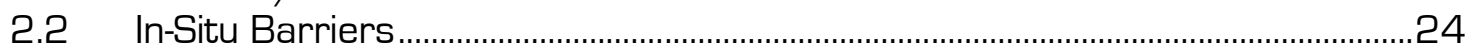

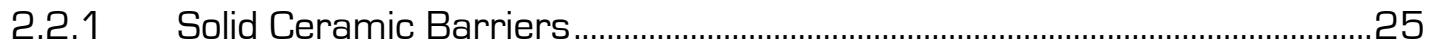

2.3 Applications to NGNP ………………………………………………………....26

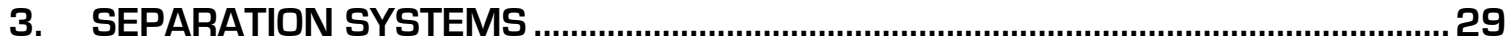

3.1 Tritium Permeation Windows ………………………………………………..29

3.1.1 Permeation Window Materials.........................................................................29

3.1.2 Contaminant Effects ........................................................................................33

3.1.3 Permeator Shapes................................................................................................33

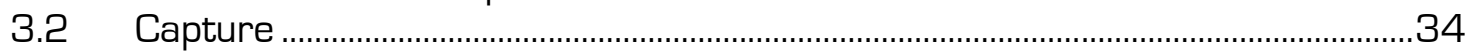

3.2.1 Purge Streams .................................................................................................35

3.2.2 Post-Permeator Evacuation or Flushing .........................................................35



3.2.4 Chemical Transformation ..................................................................................40

3.3 Disposition or Disposal...........................................................................................43

3.4 Applications to NGNP ..........................................................................................43

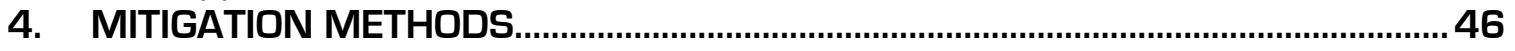

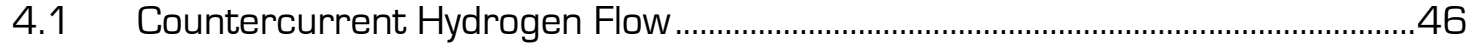

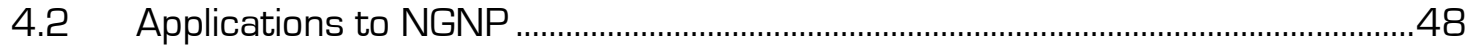

5. RESEARCH AND DEVELOPMENT NEEDS FOR NGNP.........................................50 


\section{TABLE OF FIGURES}

Figure 1. Schematic of Next Generation Nuclear Plant (NGNP) with hydrogen production plant.............................................................................. 1

Figure 2. Artist's conception of the NGNP (left) featuring a hydrogen production plant (top) and a chemical plant (right).

Figure 3. Diffusion, bulk transport and permeation pathways of tritium in a heat transfer loop system.

Figure 4. Schematic of NGNP using a High Temperature Steam Electrolysis (HTSE)

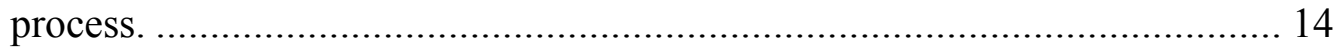

Figure 5. Tritium material balance for NGNP using HTSE process. ......................... 14

Figure 6. Tritium concentration in the product hydrogen as a function of the ratio of heat exchanger tritium permeability to the base metal tritium permeability for an NGNP employing HTSE, as calculated by THYTAN. ........................... 18

Figure 7. Tritium concentration in the hydrogen product from a Sulfur-Iodine hydrogen plant powered by the NGNP as a function of the PHX tritium permeability. . 19

Figure 8. Tritium concentration in the hydrogen product from a Sulfur-Iodine hydrogen plant powered by the NGNP as a function of the SHX tritium permeability. . 19

Figure 9. Comparison of hydrogen permeabilities of stainless steel to various ceramics.

Figure 10. Drawings of the Sandia SiC Sulfuric Acid Decomposer. .......................... 27

Figure 11. Measured permeabilities of several corrosion-resistant transition metals.... 30

Figure 12. Plate and tubular hydrogen separation membranes described by Endlund [62].

Figure 13. Equilibrium pressure of selected metal or alloy hydrides as a function of temperature based upon van't Hoff equation [66]................................. 38

Figure 14. Isothermal pressure-volume curves for zirconium-hydrogen system at temperatures between $600^{\circ} \mathrm{C}$ and $900^{\circ} \mathrm{C} . \mathrm{A}=600^{\circ} \mathrm{C} ; \mathrm{B}=700 ; \mathrm{C}=750 ; \mathrm{D}=800$; $\mathrm{E}=825 ; \mathrm{F}=850 ; \mathrm{G}=875 ; \mathrm{H}=900^{\circ} \mathrm{C}$. Reproduced from Edwards et al. [70].... 39

Figure 15. Hydrogen equilibrium pressure curves for yttrium/hydrogen system. Reproduced from Yannopoulos et al. [71]....

Figure 16. Calculated tritium activity in the NGNP hydrogen product from an HTE plant as a function of water vapor injection rate in the secondary loop helium coolant.

Figure 17. Calculated tritium activity in the NGNP tertiary loop helium coolant hydrogen as a function of water vapor injection rate in the secondary loop helium coolant. ..................................................................... 42

Figure 18. Reduction ratios of deuterium flux in response to hydrogen counter flux through a nickel membrane at several hydrogen partial pressures. 46 


\section{TABLE OF TABLES}

Table 1. Tritium Source Terms for Several HTGRs..................................................... 4

Table 2. Regulatory constraints on tritium emissions in the United States...................... 5

Table 3. Measured Permeation Reduction Factors from Yao et al............................... 23

Table 4. Permeabilities of Pd-Ag Compared to Several Structural Metals.................... 32

Table 5. Recommendations for R\&D of Tritium Barriers/Separation Systems for the

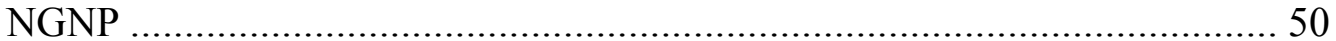




\section{INTRODUCTION}

\subsection{Next Generation Nuclear Plant (NGNP)}

The Next Generation Nuclear Plant (NGNP) is envisioned as consisting of a high-temperature gas-cooled nuclear reactor (HTGR), gas-driven or steam-driven electrical generators, a hightemperature heat transfer loop, and thermal energy delivery systems capable of providing high temperature heat to a hydrogen production plant or other down-stream industrial process (e.g., coal-to-liquids plant, petroleum refinery, underground fossil fuel recovery). A basic schematic of the NGNP featuring a hydrogen production plant is shown in Figure 1. An artist's conception of this plant is shown in Figure 2.

The HTGR, or more specifically a VHTR (Very High Temperature Gas-Cooled Reactor), is a helium-cooled, graphite moderated, thermal neutron spectrum nuclear reactor that will operate at a nominal pressure between 5-9 $\mathrm{MPa}$ and an outlet temperature between $800-950^{\circ} \mathrm{C}$ [1]. The development of the HTGR for this application builds upon earlier gas-cooled nuclear reactor experiences including Dragon, Peach Bottom, Fort St. Vrain, PNP, and others [2, 3]. The reactor will employ tri-isotopic (TRISO)-coated uranium fuel and can be constructed using either a prismatic or pebble bed core. The reactor will contain passive safety features, and would be capable of withstanding a postulated long-term, depressurized, loss-of-forced-convection accident without damaging the fuel. The VHTR is one of six reactor concepts recommended by the Generation IV Technology Roadmap for further development [4] and the NGNP is the top priority in the U.S. Generation IV Implementation Strategy [5].

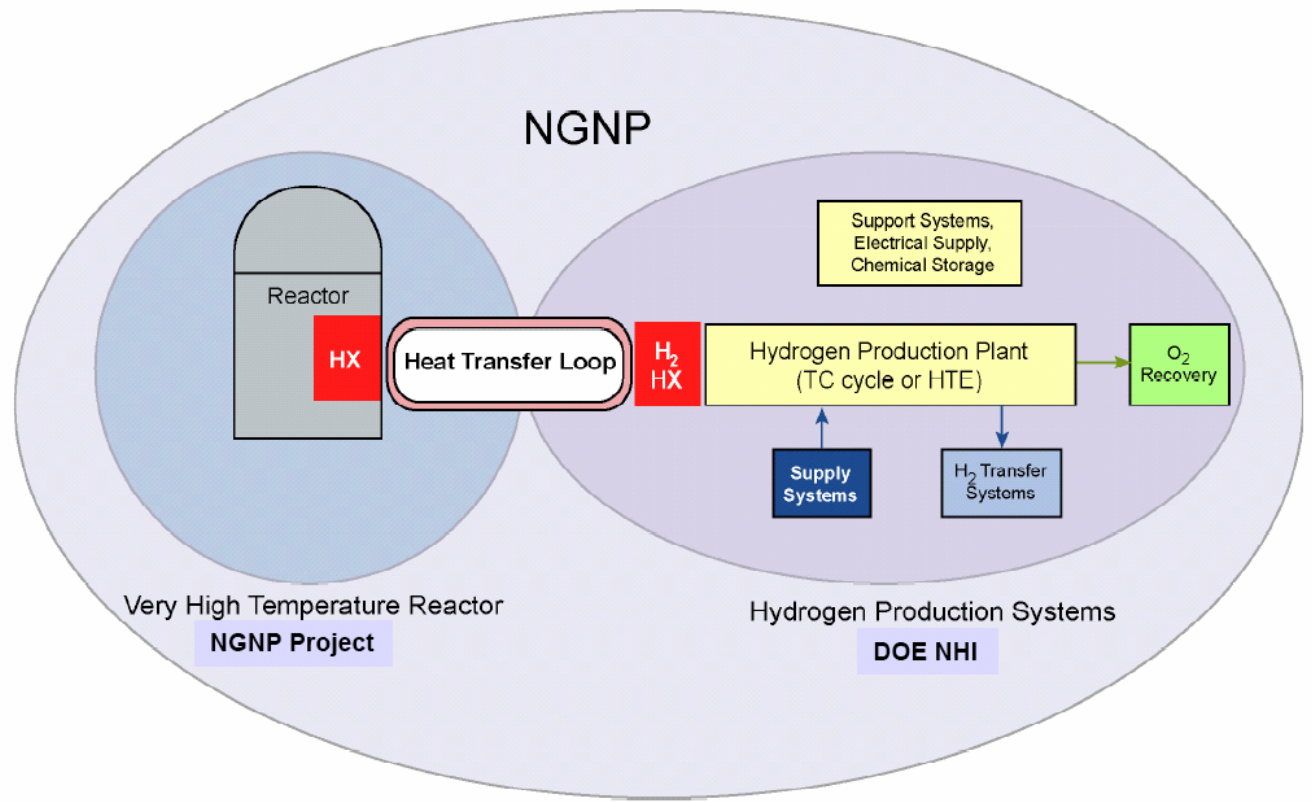

Figure 1. Schematic of Next Generation Nuclear Plant (NGNP) with hydrogen production plant. 




Figure 2. Artist's conception of the NGNP (left) featuring a hydrogen production plant (top) and a chemical plant (right).

In 2005, the U.S. Congress passed the Energy Policy Act (EPACT 2005 [6]) which authorized the creation of the NGNP Project and provided performance targets. In Section 641, the Act states that the Project shall consist of research, development, design, construction, and operation activities for a prototype plant that includes a nuclear reactor supported by the Generation IV Nuclear Energy Systems Initiative, that produces electricity or hydrogen or both, and that start-up of the prototype will occur no later than the end of FY 2021 (September 2021). The Act calls for placement of the NGNP at the Idaho National Laboratory (INL). Major program elements described in the Act include

- High-temperature hydrogen production technology development and validation

- Power conversion technology development and validation

- Nuclear fuel development, characterization and qualification

- Materials selection, development, testing and qualification

- Reactor and balance-of-plant (BOP) design, engineering, safety analysis, and qualification.

As a result of this Act, the U.S. Department of Energy (DOE) selected the INL to lead the development of the NGNP by integrating and coordinating all necessary research and development activities, and by coordinating project efforts with industry and other Project participants. The nuclear reactor will be licensed by the U.S. Nuclear Regulatory Commission (NRC) under a commercial license.

\subsection{Tritium}

A distinguishing characteristic of the NGNP from established commercial nuclear plants is the presence of a thermal energy connection between the nuclear plant and a non-nuclear user of high-temperature heat. In the NGNP, thermal energy is delivered from the core of the nuclear 
reactor to a downstream user without the intermediate conversion of thermal energy into electrical energy, and this is accomplished by heat transfer through heat exchangers and the bulk movement of heat transfer fluids through conduits. While direct heat transfer is more efficient than using an intermediate electricity conversion step, a direct heat transfer pathway provides an opportunity to transport fission products, particularly tritium, from the nuclear reactor into the downstream plant.

Tritium is a radioactive form of hydrogen. Its molecular weight is $3.016 \mathrm{amu}$ and it has a half-life $t_{1 / 2}$ of 12.33 years. One gram of tritium is equivalent to approximately $9,600 \mathrm{Ci}$. Tritium is produced in the core of the reactor as a by-product of the uranium fission reactions, and acts as a contaminant in the nuclear reactor heat transfer streams. Tritium is a weak beta emitter $(0$ to $18.6 \mathrm{keV}$ ), and decays to ${ }^{3} \mathrm{He}$ upon disintegration. The primary route of tritium exposure in living things is through the ingestion or absorption of tritiated water. Apart from a difference in mass, tritium behaves chemically as hydrogen [7]. Tritium, like hydrogen, is highly mobile and can readily permeate into and through materials, especially metals, at higher temperatures, and this permeation is the cause of hydrogen embrittlement under some conditions. Due to the potential health hazard from the ingestion or absorption of tritium, tritium emissions to the environment are regulated by the NRC and the U.S. Environmental Protection Agency (EPA).

Since tritium behaves chemically as hydrogen, it can undergo isotope exchange reactions with hydrogen-containing chemicals (e.g., $\mathrm{H}_{2} \mathrm{O}, \mathrm{H}_{2}, \mathrm{CH}_{4}$, etc.) in downstream industrial processes and become incorporated into the plant's process chemicals or products, and incorporation of tritium in any significant amount may lead to a number of problems. Maintenance of the downstream facilities becomes more complicated because radiation dose to workers becomes a consideration. The downstream facilities may not be licensed or permitted to operate as a nuclear facility, and excessive contamination of the plant by tritium may push it into the nuclearregulated regime. Also, customers of the downstream facilities may have little to no tolerance for a radioactive product, and so contamination of downstream facilities with tritium may lead to rejected product and loss of revenue for the plant.

The simplest solution to preventing tritium contamination of downstream facilities is to sever the thermal connection between the nuclear plant and the downstream user, but this negates the energy efficiency potential that is integral to the NGNP as a supplier of high-temperature heat. Therefore, the next best solution is to prevent tritium from reaching the downstream user in any significant amount, and multiple means to accomplish this are described in this report. The principal methods that may be employed are to reduce the tritium permeability of heat exchangers through various means, and to deploy tritium separation systems on the heat transfer fluid loops in order to remove tritium from those streams, thus making it unavailable to downstream processes. In the following subsections, the origins of tritium in the nuclear reactor are more fully described, and the mechanisms for transport of tritium from the core to the downstream process are discussed. Also, the concept of an overall tritium mass balance is described, so that the tritium countermeasures offered later in the report can be understood in regard to their purpose and targeted effects.

\subsubsection{Tritium Generation}

In the NGNP, tritium is produced in the core of the nuclear reactor by the ternary fission of uranium $\left({ }^{233} \mathrm{U},{ }^{235} \mathrm{U}\right)$ and plutonium $\left({ }^{239} \mathrm{Pu},{ }^{241} \mathrm{Pu}\right)[8,9]$, and by the interaction of neutrons with lithium, boron, and helium impurities in the surrounding core graphite and helium cooling fluid [2], as shown in Equations 1 through 5. 
${ }^{6} \mathrm{Li}(\mathrm{n}, \alpha){ }^{3} \mathrm{H}$

${ }^{7} \mathrm{Li}(\mathrm{n}, \mathrm{n} \alpha){ }^{3} \mathrm{H}$

${ }^{3} \mathrm{He}(\mathrm{n}, \mathrm{p}){ }^{3} \mathrm{H}$

${ }^{10} \mathrm{~B}(\mathrm{n}, 2 \alpha){ }^{3} \mathrm{H}$

${ }^{10} \mathrm{~B}(\mathrm{n}, \alpha){ }^{7} \mathrm{Li}$.

Tritium is generated at defined rates according to the power level and the neutron activity in the core and is not limited by the concentration of tritium already present in the core coolant stream. In nuclear parlance, the tritium creation rate is known as the tritium source term [10].

The tritium source term for the NGNP is not yet determined, but source terms from past hightemperature gas-cooled reactors have been calculated [2]. Table 2 shows calculated tritium source terms for Peach Bottom, Fort St. Vrain, U.K.'s 1500-MW HTGR, U.K.'s 3000-MW HTGR, and Germany's PNP-500. These numbers were obtained from data collected during reactor operation.

Table 1. Tritium Source Terms for Several HTGRs

\begin{tabular}{|c|c|c|c|c|c|}
\cline { 2 - 6 } \multicolumn{1}{c|}{} & $\begin{array}{c}\text { Peach Bottom } \\
(66.5 \mathrm{MW})\end{array}$ & $\begin{array}{c}\text { Fort St. Vrain } \\
(842 \mathrm{MW}) \\
6^{\text {th }} \text { year }\end{array}$ & $\begin{array}{c}\text { 1500-MW } \\
\text { HTGR }\end{array}$ & $\begin{array}{c}\text { 3000-MW } \\
\text { HTGR }\end{array}$ & $\begin{array}{c}\text { PNP-500 } \\
\text { MW }\end{array}$ \\
\hline $\begin{array}{c}\text { Fission } \\
(\mathrm{Ci} / \text { year })\end{array}$ & 283 & 2,730 & 9,950 & 11,000 & 3,190 \\
\hline${ }^{6} \mathrm{Li}(\mathrm{Ci} /$ year $)$ & 15.1 & 481 & 1,190 & 2,810 & 150 \\
\hline${ }^{3} \mathrm{He}(\mathrm{Ci} /$ year $)$ & 14.7 & 370 & 4,540 & 3,680 & 2,000 \\
\hline${ }^{10} \mathrm{~B}(\mathrm{Ci} /$ year $)$ & 206 & 330 & Unavailable & 919 & 260 \\
\hline $\begin{array}{c}\text { Total } \\
(\mathrm{Ci} / \text { year })\end{array}$ & 519 & 3,911 & 15,680 & 18,409 & 5,600 \\
\hline
\end{tabular}

\subsubsection{Regulatory Limits}

In the U.S., tritium emissions are regulated by the NRC and the EPA. Regulatory limits are shown in Table 2. The minimum level of protection to the public is provided by 10 CFR 20 under the jurisdiction of the NRC. Under these rules, exposure of the public to tritium from regular operations of a licensed nuclear facility is limited to less than $100 \mathrm{mrem} /$ year. The amount of tritium providing the exposure is not defined, and only the resulting dose to the public is the relevant factor. A licensee can demonstrate compliance with the $100 \mathrm{mrem} / \mathrm{year}$ limit by limiting tritium releases in gaseous and liquid effluents to less than the limits provided in Table 2 of Appendix B to 10 CFR 20. The NRC regulations (10 CFR 20.1301(e)) also require that nuclear operators comply with the EPA limits set forth in 40 CFR Part 190, which state that exposure to 
radiation of the general public from the nuclear fuel cycle is limited to $25 \mathrm{mrem} / \mathrm{year}$ for the whole body.

Table 2. Regulatory constraints on tritium emissions in the United States

\begin{tabular}{|c|c|c|c|c|c|c|c|}
\hline & \multirow[b]{3}{*}{ Regulation } & \multirow{2}{*}{\multicolumn{2}{|c|}{$\begin{array}{c}\text { Annual Radiation } \\
\text { Dose }\end{array}$}} & \multicolumn{4}{|c|}{ Effluent Concentration } \\
\hline & & & & \multicolumn{2}{|c|}{ Air } & \multicolumn{2}{|c|}{ Water } \\
\hline & & (mrem) & $(\mathrm{mSv})$ & $(\mu \mathrm{Ci} / \mathrm{ml})$ & $(\mathrm{Bq} / \mathrm{ml})$ & $(\mu \mathrm{Ci} / \mathrm{ml})$ & $(\mathrm{Bq} / \mathrm{ml})$ \\
\hline \multirow[t]{2}{*}{ Limit } & 10 CFR 20.1301(a)1 & 100 & 1 & - & - & - & - \\
\hline & $\begin{array}{l}\text { Table } 2 \text { of Appendix B } \\
\text { to } 10 \text { CFR } 20\end{array}$ & 50 & 0.5 & $1 \mathrm{E}-7$ & $3.7 \mathrm{E}-3$ & $1 \mathrm{E}-3$ & 37 \\
\hline Standard & 10 CFR 20.1301(e) & 25 & 0.25 & $(5 \mathrm{E}-8)^{\mathrm{a}}$ & $(1.85 \mathrm{E}-3)^{\mathrm{a}}$ & $(5 \mathrm{E}-4)^{\mathrm{a}}$ & $(18.5)^{\mathrm{a}}$ \\
\hline \multirow[t]{2}{*}{ ALARA } & \multirow{2}{*}{$\begin{array}{l}\text { Appendix I to } \\
10 \text { CFR } 50\end{array}$} & 20 ( $\beta$,air $)$ & 0.20 & $(4 \mathrm{E}-8)^{\mathrm{a}}$ & $(1.48 \mathrm{E}-3)^{\mathrm{a}}$ & - & - \\
\hline & & 3 (water) & 0.03 & - & - & $1.5 \mathrm{E}-5$ & 0.56 \\
\hline $\begin{array}{l}\text { Drinking } \\
\text { Water }\end{array}$ & EPA standard & 4 & 0.04 & - & - & $2 \mathrm{E}-5$ & 0.74 \\
\hline \multicolumn{8}{|c|}{$\begin{array}{l}\text { a. Calculated by assuming the linear relationship between the annual dose of } 50 \mathrm{mrem} \text { and the values in } \\
\text { Table } 2 \text { of Appendix B of } 10 \text { CFR } 20 . \\
\text { ALARA = as low as reasonably achievable } \\
\text { CFR = Code of Federal Regulations }\end{array}$} \\
\hline
\end{tabular}

The NRC has established ALARA (As Low As Reasonably Achievable) design limits for nuclear facilities. These are limits that must not be exceeded during the design of nuclear reactors and other regulated facilities. The limits provide the maximum dose limit to the public for whole-body exposure due to air or water contaminated with tritium.

Outside of the NRC, the EPA prescribes a standard for limiting tritium in drinking water under the authority of the Safe Drinking Water Act $(1974,1986,1996)$. This limit is 4 mrem/year. The standard does not apply to drinking wells, though many states have chosen to use the federal standard to regulate the permissible tritium levels in water from drinking wells.

There are no limits or standards established for tritium in commercial non-nuclear processes in the U.S. except those set by the EPA for drinking water (4 mrem/year) and for whole-body dose (25 mrem/year) from radiation emitted by the nuclear fuel cycle, of which tritium can be considered a by-product. The State of California (U.S.) has recently established a public health goal of no more than $400 \mathrm{pCi} / \mathrm{L}$ in drinking water, or a factor of 37.5 times smaller than the NRC ALARA limit, which was established to cause no more than an increase of $1 \times 10^{-6}$ in the probability of causing cancer in an individual given a daily exposure of $2 \mathrm{~L} /$ day over a lifetime [11]. The State of California still retains the federal limit of $20,000 \mathrm{pCi} / \mathrm{L}$.

Other countries have imposed their own tritium limits in non-nuclear products. Germany, for example, established a limit of $0.5 \mathrm{~Bq} / \mathrm{g}(13.5 \mathrm{pCi} / \mathrm{g})$ for any non-nuclear product, which, when applied to water, would be under the NRC ALARA limits [12]. The European Union has adopted a drinking water limit of $100 \mathrm{pCi} / \mathrm{L}$ as a screening criterion, above which more detailed examination of the sample must be performed to look for other radioactive contaminants [13]. Countries such as Finland, Australia, Russia, and Switzerland have also established drinking 
water limits for tritium. No published standards have yet been issued for the tritium limit in hydrogen product streams.

Since the NGNP is in the conceptual design stage at this point in time, and is targeted for construction and operation in the U.S., the most appropriate limits for regulating the amount of tritium released into the environment in the air or liquid effluents are the ALARA limits established in Appendix I of 10 CFR 50 by the NRC. All tritium barrier and separation systems adopted for the NGNP in the design stage must provide a calculated level of protection that is less than or equal to the ALARA limits provided in Table 2. In the context of the NGNP, this can be interpreted as providing limits to the amount of tritium that can be emitted to a downstream user of high-temperature heat who is not regulated by the NRC. Though tritium emitted to a downstream hydrogen plant or chemical plant may be diluted further before it is released to the environment as a consequence of the downstream processes, no credit can be taken for any future dilution mechanism that has yet to be fully defined, and the existing ALARA limits must be adopted at the entry point to any downstream process (i.e., at the process heat exchanger) as a conservative rule until further information is obtained about any potential downstream process.

\subsubsection{Transport Mechanisms}

The mechanisms for transport of tritium from the nuclear core to a downstream process are diffusion, bulk transport, and permeation. Diffusion occurs in the heat transfer fluids, and tritiumcontaining species (i.e., $\mathrm{T}_{2}$, HT, HTO, etc.) move from areas of higher tritium concentration to areas of lower tritium concentration by virtue of random molecular movements. Superimposed on the gaseous diffusion mechanism is the bulk transport of the heat transfer fluid itself, in which the tritium species are transported. The third mechanism is permeation, which involves the transport of tritium through the solid heat exchanger surfaces. Permeation is an extension of diffusion in that the movement of tritium is from areas of higher concentration to lower concentration, but may involve multiple chemical and physical steps in order to achieve transport of tritium across the solid material. These mechanisms are shown graphically in Figure 3.

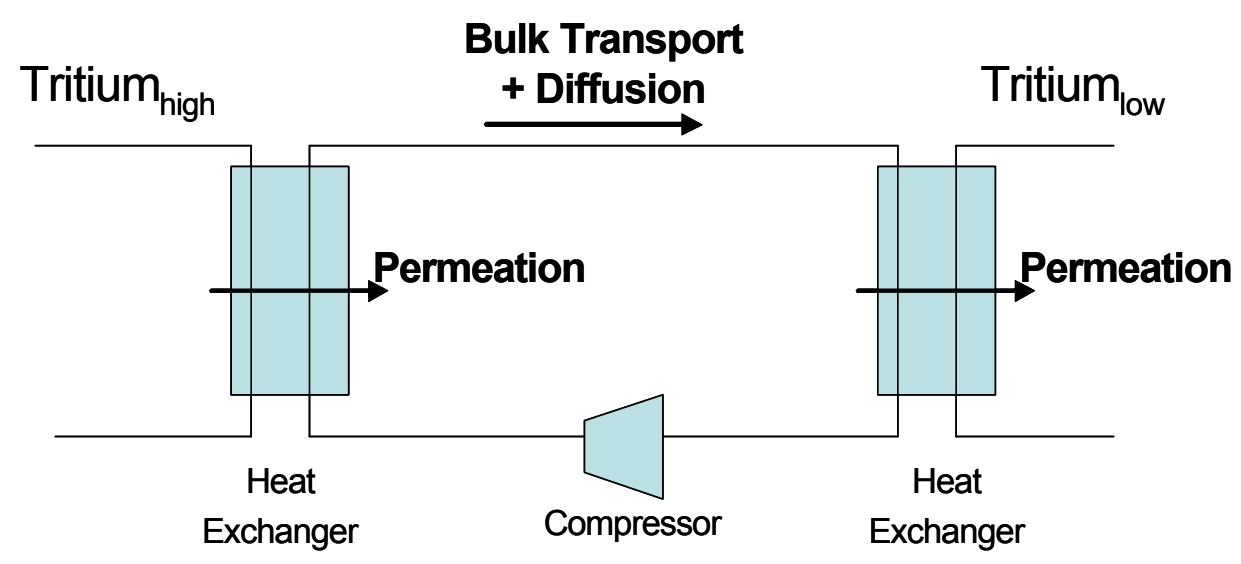

Figure 3. Diffusion, bulk transport and permeation pathways of tritium in a heat transfer loop system.

The movement of tritium or tritium-containing species is measured as a mass or molar flux, which is defined as the quantity of material that passes through a defined area normal to the flow of material per unit time. The frame of reference may be fixed in space or may be moving at the 
rate of the bulk flow of material. In the case of the heat exchangers, the frame of reference is fixed because the heat exchangers are stationary, and the heat exchanger walls are the material through which tritium permeates. In the bulk fluid, either frame of reference could be used, but in this case, employing a fixed frame of reference is also the most useful, because the overall heat transfer loop is stationary, and the concern is with the transport of tritium between two fixed points (the nuclear reactor core and the downstream process). If a fixed frame of reference is employed and steady-state conditions are assumed, the flux of tritium in the heat transfer loop fluid is quantified by using Fick's first law, as modified by de Groot (Equation 6) [14].

$N_{T_{i}}=-c D_{T_{i}, B} \nabla y_{T_{i}}+y_{T_{i}}\left(N_{T_{i}}+N_{B}\right)$

In Equation 6, $N_{T_{i}}$ is the molar flux of tritium species $i, c$ is the total molar concentration of the fluid (a molar density), $D_{T_{i}, B}$ is the diffusivity of tritium species $i$ in the bulk fluid $B, \nabla y_{T_{i}}$ is the multi-dimensional molar gradient of tritium species $i$ expressed as a mole fraction, $y_{T_{i}}$ is the mole fraction of tritium species $i$, and $N_{B}$ is the molar flux of the bulk medium at the point of reference. The first term in Equation 6 is the diffusion contribution to the molar flux, and the second term is the bulk transport contribution to the flux. The diffusion contribution has a negative sign because diffusion occurs from areas of high concentration to lower concentration. The diffusion and bulk transport of each tritium species can be handled independently because the tritium is dilute. Being dilute, the tritium species in the heat transfer fluid have little interaction with each other and also do not have a significant effect on the properties of the bulk heat transfer fluid.

Permeation across the heat exchangers involves the passage of mobile species through a solid material. Species may permeate a solid material by simple fluid diffusion through cracks, holes, or pores that penetrate the material. When the diameter or width of cracks, holes or pores is relatively large in relation to the length of the mean free path of the permeating species, then Equation 6 can be used to model the permeation of species through the material assuming that the bulk flow rate of fluid through the material is known or can be calculated using other physical information (material open surface area, pressure drop across the material, friction factor, etc.). When the pores are relatively small and the diameter of the pores approaches the mean free path of the solute species or the bulk fluid, then Knudsen diffusion mechanisms [15] begin to affect permeability, and the permeability of solute species and the bulk fluid begins to decouple, and selective separation of solutes from the bulk fluid may be performed on the basis of molecular size (such is the physical basis for the selectivity of microporous gas separation membranes [16]). When there is no contiguous open pathway through which a permeating species can travel, or the surface density of such pathways is relatively low so that the bulk fluid flow rate through the material is negligible, then the ability of the permeating species to dissolve into the material itself in a reversible manner most strongly influences the species' permeation rate through the material.

The permeation of a species through a solid material involves multiple steps. These steps are:

- Diffusion of permeating species from bulk fluid to material surface in response to a gradient.

- Adsorption of species onto material surface by physisorption, chemisorption, or chemical reactions. This may involve the decomposition of the adsorbing species into subelements. 
- Absorption of permeating species or species sub-elements into the solid material and diffusion of the permeating species or species sub-elements across the bulk material in response to a gradient.

- Re-emergence of the permeating species or species sub-elements on the opposite surface (desorption and recombination).

- Diffusion of permeating species or sub-elements from the opposite surface into the bulk fluid on the other side of the solid material in response to a gradient. If sub-elements are released freely, then the solid material is acting as a reactive membrane; otherwise the sub-elements must first recombine into the original permeating species before being released.

These permeation processes occur at different rates, and any one step may be the rate-limiting step for permeation of a species through a material. If the adsorption step has the slowest rate, then permeation through the material is said to be surface-limited. If the chemical kinetics of dissolution and the diffusion of the species through the material have the slowest rate, then permeation through the material is said to be bulk-limited. The arrival rates of permeating species on one side of the solid material must equal the departure rates of permeating species on the other side of the solid material in order to maintain a stable flow of permeate through the solid material. Otherwise, the solid material may become saturated with permeating species and the concentration gradient across the material will become diminished.

In metals, and especially those metals used for heat exchangers (alloys of Groups IIIB, IVB, VB, VIIB, and VIII), hydrogen can reversibly adsorb and dissolve into the base metal in atomic form, while molecular hydrogen species (e.g., $\mathrm{H}_{2} \mathrm{O}$, HI, etc.) and chemically inert solvents such as helium cannot [17]. Because of this ability to reversibly dissolve hydrogen, such metals are generally much more permeable to hydrogen than metals that strongly react with hydrogen to form hydrides (e.g., $\mathrm{Na}, \mathrm{U}$ ), or non-metallic materials that have no specific chemical affinity or limited solubility for hydrogen (e.g., oxides). It should be noted that some metal oxide materials are capable of absorbing hydrogen to form metal oxide hydroxides or hydrates such as $\mathrm{Al}_{2} \mathrm{O}_{3} \cdot \mathrm{H}_{2} \mathrm{O}$, $\mathrm{AlO}(\mathrm{OH})_{2}, \mathrm{Cr}_{2} \mathrm{O}_{3} \cdot \mathrm{H}_{2} \mathrm{O}, \mathrm{Fe}_{2} \mathrm{O}_{3} \cdot \mathrm{H}_{2} \mathrm{O}$, and others, but such metal oxide hydrates and hydroxides will generally decompose at the temperatures encountered in the NGNP cooling loops (i.e., greater than $\left.450^{\circ} \mathrm{C}\right)$ [18].

Though the individual steps in the permeation process can be envisioned, it is usually difficult to predict the permeability of hydrogen through a material based only on theory. Some experimental data are needed to model or predict hydrogen permeation through a heat exchanger material. A commonly used formula for the steady-state tritium permeation through steam generator heat transfer tubes (cylindrical geometry) [19] is shown in Equation 7.

$J=\frac{2 \pi l}{\ln (b / a)} \Phi(T)\left(p_{e q}^{x}-p_{w}^{x}\right)$

In Equation 7, $J$ is the tritium permeation rate in atoms/s, $l$ is the length of the tube in meters, $b$ is the outer diameter of the tube, $a$ is the inner diameter of the tube, $\Phi(T)$ is the permeability of the heat exchanger material as measured in atoms $/ \mathrm{m} \cdot \mathrm{s} \cdot \mathrm{Pa}^{\mathrm{n}}$ and is a function of temperature $T$, $p_{e q}^{x}$ is the equivalent partial pressure or activity of hydrogen (includes all combinations of $\mathrm{H}, \mathrm{D}$, and $\mathrm{T}$ ) in the bulk fluid, and $p_{w}^{x}$ is the equivalent partial pressure or activity of hydrogen in water. The equation is time-independent, and assumes constant $T$ and $p^{x}$. The permeation coefficient of 
the material, $\Phi(T)$, and the superscript $x$ are determined experimentally, and permeation coefficients may be available for materials of interest in the literature. The superscript $x$ is pressure-dependent and varies between 0.5 and 1.0, depending upon whether permeation is bulklimited $(x=0.5)$ or surface-limited $(x=1.0)$. In the literature, bulk-limited permeation is explained by the formation of an imperfect barrier, which blocks most but not all adsorption sites on the underlying surface, while a surface-limited process would involve a dense barrier layer where no adsorption sites are accessible, and tritium must permeate through the barrier layer in order to access the underlying material. The highest resistance to permeation occurs when the tritium permeation process is surface-limited, and the measurement of an exponent close to 1.0 is usually taken as an indication of a very effective barrier layer. The superscript $x$ is not directly dependent upon heat exchanger geometry, and measurements obtained from the examination of smaller tubes or coupons can be extrapolated to model larger heat exchangers if the surface and bulk chemistry conditions are similar. One method to distinguish between bulk and surface control mechanisms is to perform experiments using different tube sizes, and then using Equation 7 (or 8 below) to determine the exponent. If bulk control mechanisms are occurring, then the measured flux may be independent of diameters $a$ and $b$.

In the case of a helium-to-helium heat exchanger [20], the partial pressure term in Equation 7 is replaced to form Equation 8.

$J=\frac{2 \pi l}{\ln (b / a)} \Phi(T)\left(p_{2}^{x}-p_{1}^{x}\right)$

In Equation $8, p_{1}^{x}$ is the equivalent partial pressure or activity of tritium on the upstream side of the heat exchanger wall, and $p_{2}^{x}$ is the equivalent partial pressure or activity of tritium on the downstream side of the heat exchanger. When $x=0.5$, Equation 8 is also referred to as

Richardson's Equation (which is based on Sievert's Law), and $\Phi(T)$ is referred to as a Sievert's constant [21]. Sievert's Law states [22] that the concentration of hydrogen dissolved in a metal, $c_{H_{2}}$, is proportional to the square root of the partial pressure of hydrogen in contact with the metal surface, $p_{\mathrm{H}_{2}}^{0.5}$, as shown in Equation 9.

$c_{H_{2}}=K p_{H_{2}}^{0.5}$

The permeability constant $K$ or Sievert's constant is known for a number of heat exchanger materials over a range of temperatures. The permeability coefficient $\Phi(T)$ is related to Sievert's constant by Equation 10, where $D$ is the diffusivity of tritium through the material of interest [23].

$$
\Phi(T)=K D
$$

For a flat plate, Equation 8 is modified to adjust for the area of the plate as shown in Equation 11.

$$
J=\frac{A}{t} \Phi(T)\left(p_{2}^{x}-p_{1}^{x}\right)
$$


In Equation 11, $A$ is the plate area, and $t$ is the thickness of the heat exchanger plate. Richardson's Equation is used to calculate the permeability of hydrogen through metallic membranes. Note that Equations 10 and 11 are steady-state equations, and that constant temperature and $p^{x}$ are assumed. During changing conditions, unsteady-state forms of these equations would need to be used instead to model the flux.

The temperature dependence of Sievert's constant has been observed to be exponential and conforms to the Arrhenius Equation [24]. The Arrhenius form of Sievert's constant is shown in Equation 12.

$\Phi(T)=\Phi_{H_{2}}^{0} \exp \left(-E_{a} / R T\right)$

In Equation 12, $\Phi_{\mathrm{H}_{2}}^{0}$ is the pre-exponential factor, $E_{a}$ is the apparent activation energy, $R$ is the ideal gas constant, and $T$ is the temperature.

When Equations 7-11 are used, it is assumed that the heat exchanger is leak-free (no cracks, holes, or pores), and only hydrogen species can penetrate the heat exchanger. This assumption can be checked by performing a leak test of the heat exchanger to quantify any cross-leakage of the bulk fluid $[25,26]$. If leaks are detected in an individual heat exchanger, then multiple mechanisms may be operating simultaneously, and the transport of tritium across the heat exchanger surfaces will be dependent upon the additive effects of bulk (or Knudsen) diffusion mechanisms, and diffusion of atomic tritium through the solid surfaces.

The chemical form of tritium influences the transport properties. In the nuclear reactor core, tritium is released to the coolant as $T_{2}$, but will quickly undergo isotope exchange reactions with molecular hydrogen, present as a contaminant in the helium stream, to form tritiated hydrogen [27], as shown in Equation 13.

$\mathrm{T}_{2}+\mathrm{H}_{2}=2 \mathrm{HT}$

Since hydrogen is usually available at concentrations in excess of the tritium concentration, the most common molecular form of tritium in the coolant is HT. On an atomic basis, deuterium and tritium have 2 and 3 times the mass of hydrogen (protium), respectively. The permeabilities of deuterium and tritium are observed to be approximately $1 / \sqrt{2}$ and $1 / \sqrt{3}$ times that of protium when the permeator is bulk-controlled, all other factors being equal [28], and this forms the basis of some hydrogen isotope separation techniques [22]. The isotope exchange reaction occurs at a rapid rate, and the distribution of reaction product and reactants is characterized by a chemical equilibrium. The equilibrium constant of the reaction is generally greater than 1 and varies with temperature.

Water may also be present as an impurity in the heat transfer fluids, and HT can interact with water to form tritiated water, as shown in Equation 14.

$\mathrm{HT}+\mathrm{H}_{2} \mathrm{O}=\mathrm{HTO}+\mathrm{H}_{2}$

Though hydrogen in gaseous form has a high permeability through metals at high temperatures, Nakamura and Nishi [28] observed that tritium from tritiated water has a permeability about $10^{3}$ smaller than gaseous tritium, which most likely results from the decomposition of tritiated water on the surface of the metal, followed by permeation of the tritium species through the metal. The 
equilibrium constant of Equation 14 is near 5 at room temperature and approaches 1.5 as the temperature is increased above $800^{\circ} \mathrm{C}$, indicating that the isotope exchange reaction between tritiated hydrogen and water is less favored at higher temperatures than at lower temperatures.

In a downstream chemical process, tritium will undergo isotope exchange reactions with other hydrogen-containing species, and this can also affect the degree to which tritium contaminates a downstream product or is retained inside a chemical plant in some less transportable form. For example, the Sulfur-Iodine and Hybrid Sulfur cycles [29, 30] use sulfuric acid as part of their process, and tritium can undergo an isotope exchange reaction with the sulfuric acid to form tritiated sulfuric acid, $\mathrm{HTSO}_{4}$, as shown in Equations 15 and 16.

$\mathrm{HT}+\mathrm{H}_{2} \mathrm{SO}_{4}=\mathrm{H}_{2}+\mathrm{HTSO}_{4}$

$\mathrm{HTO}+\mathrm{H}_{2} \mathrm{SO}_{4}=\mathrm{H}_{2} \mathrm{O}+\mathrm{HTSO}_{4}$

Chemically, sulfuric acid does not permeate most structural materials unless they are porous or cracked. It also has a relatively high boiling point $\left(338^{\circ} \mathrm{C}\right.$ at $98.3 \%$ purity) and is not as mobile as hydrogen. Above $450^{\circ} \mathrm{C}, \mathrm{H}_{2} \mathrm{SO}_{4}$ decomposes into $\mathrm{SO}_{3}$ and $\mathrm{H}_{2} \mathrm{O}$, which releases any tritium held in the sulfuric acid molecule in the form of tritiated water. So, in the portions of the chemical plant containing sulfuric acid, it can be expected that tritium will accumulate to a certain equilibrium level and further analyses are warranted to determine whether the concentration of tritium in the sulfuric acid section of the plant would be sufficiently high that additional radiation and radioactive contamination controls are necessary in order to perform work on process units or when considering disposal of process chemicals.

The Sulfur-Iodine process also uses iodine, and HI can interact with tritium species to form tritium iodide, as shown in Equations 17 and 18.

$\mathrm{HT}+\mathrm{HI}=\mathrm{H}_{2}+\mathrm{TI}$

$\mathrm{HTO}+\mathrm{HI}=\mathrm{H}_{2} \mathrm{O}+\mathrm{TI}$

TI, like HI, dissolves readily in liquid water, and is less mobile than hydrogen in the vapor phase. As was the case in the sulfuric acid section of the plant, the HI section of the plant is susceptible to an accumulation of tritium up to certain equilibrium concentrations in the various process units, and further analyses are warranted to determine whether these concentrations would be sufficiently high that additional radiation and radioactive contamination controls are necessary in order to perform work on certain process units or when considering disposal of process chemicals.

The equilibrium constants of the tritium isotope exchange reactions with $\mathrm{H}_{2} \mathrm{SO}_{4}$ and $\mathrm{HI}$ are not well known, but are assumed to be close to 1 .

If the downstream process is a biomass, coal-to-liquids, steam-methane reforming, or other such plant, then additional tritium isotope exchange reactions will occur, and this will affect the tritium loss pathways and the tritium concentrations in various downstream process units.

\subsubsection{Tritium Mass Balances}

The fundamental material balance is shown below, Equation 19. The terms in Equation 19 are expressed as rates (mass per unit time, moles per unit time, Ci per unit time, etc.). 
In - Out + Formed - Destroyed $=$ Accumulation (or depletion)

In this balance, material enters a system as a component of one or more input streams or by a creation process within the system, and material leaves a system either as a component of one or more output streams or by a destruction process within the system. Since the material balance is a sum of rates, it is time-dependent, and the total amount of material existing within a system is determined by integrating the material balance over time. If the inputs and outputs are not balanced, then material will accumulate or be depleted from the system. The balance is limited by physical laws, and a system cannot be depleted below a zero material balance. For the NGNP and tritium, the balance is somewhat simplified because the input streams are assumed to be tritium-free, and the destruction term, the radioactive decay of tritium, is expected to have only a weak effect on the tritium balance relative to formation and tritium loss terms on the time scales involved. This simplified expression is shown in Equation 20.

Formed - Out - Destroyed $=$ Accumulation (or depletion)

At steady-state, the accumulation term approaches zero as the formation rate of tritium approaches the rate of tritium lost through leaks, permeation mechanisms, and radioactive decay. In an actual plant, a steady state condition may or may not be reached in a finite amount of time, and the accumulation of tritium in reactor fluid streams and absorbed into core materials may continue for an indefinite period of time, especially if the leakage rate of bulk coolant is very low and the production rate of tritium in the core is also low. Mass balances alone are insufficient to answer whether a steady-state condition is reached, and time-dependent models of tritium accumulation are needed to determine if and when a steady-state condition is reached over a defined period of time.

While the tritium creation and destruction terms are a function of nuclear interactions, the output or loss terms are dependent upon complex physical and chemical factors. Tritium is lost by the bulk leakage of contaminated coolant from the nuclear reactor and secondary heat transfer systems to the outside environment, and the amount of tritium lost per unit time is dependent upon the leak rate and the concentration of tritium in the leakage stream. Tritium will also be lost by permeation of tritium through heat transfer conduit materials and heat exchangers, and this is dependent upon the concentration or chemical activity of tritium in the heat transfer fluid, the temperature, and the permeability of the conduit wall materials. The permeability of conduit and heat exchanger materials may also depend on time-at-temperature, aging of the material during operations, extent of material oxidation, the operating history of the materials, and the presence or absence of other contaminants in the coolant stream that can affect the surface chemistry of the materials. Some materials deployed within the nuclear reactor system may have some capacity to adsorb or absorb tritium from the bulk coolant and immobilize it, and isotope exchange reactions may convert tritium into less mobile forms. Once adsorbed, absorbed, or converted into a less mobile form, tritium stored in such locations may be released again as tritiated hydrogen or water if the physical or chemical conditions change, and these mechanisms must be understood as well, though the tritium release mechanisms may take place at slower rates than the uptake mechanisms.

Because of the complexity of the loss terms, detailed dynamic models are needed to calculate the tritium material balance. One such model that has been developed is THYTAN, developed by JAEA [2]. The model employs a link-node calculation scheme that divides the system being analyzed into a series of nodes representing the various components of the system. The nodes are assigned a volume, and the material balance equation is calculated for each node according to the function and physical conditions of the node. The nodes are linked to each other, and the overall 
system is analyzed dynamically, with the outputs from one node feeding into other nodes, and the calculations are carried out iteratively in time steps until a desired total time is reached or a steady-state condition is achieved.

Figure 4 shows a schematic for one possible configuration of the NGNP, and Figure 5 shows the tritium material balance calculated for this configuration using the THYTAN model. In this configuration, a $600 \mathrm{MWt}$ VHTR is used to generate electricity and to provide high-temperature heat to a high-temperature steam electrolysis (HTSE) plant used for making hydrogen [31]. Three heat transfer loops are assumed - a primary loop, a secondary loop, and a tertiary loop. The primary loop is a helium loop used to remove thermal energy from the core and provides the full power load of the nuclear reactor to an intermediate heat exchanger. A secondary helium loop is used to drive electrical turbines, and to provide thermal energy to a second intermediate heat exchanger. The second intermediate heat exchanger connects to a tertiary helium loop, which is used to provide thermal energy to the HTSE plant. Eighty-nine percent of the thermal energy from the nuclear reactor is used to drive electrical turbines, while $11 \%$ of the thermal energy is sent to the hydrogen production plant. Steady-state operation is assumed, and it was assumed that no tritium was adsorbed or absorbed by materials in the system. The tritium source term was assumed to scale by reactor power level, and the tritium generation rate for Fort St. Vrain was used as the reference point. According to the example case calculated in [31], 0.3\% of the tritium created in the core is lost to the outside through leaks, $96.2 \%$ is removed through the use of dedicated purification systems, and $3.4 \%$ is lost to the hydrogen production plant.

The tritium material balance must be known in order to understand how tritium contamination in the downstream processes can be controlled because changing the efficacy of any one removal mechanism affects the performance or the tritium load on all other removal mechanisms. For example, placing a perfect tritium barrier between the nuclear plant and a downstream plant would eliminate the concern of contaminating downstream processes, but tritium is always being produced by the nuclear reactor, and that tritium must go somewhere if it cannot reach the downstream process. Therefore, the concentration of tritium in the fluids upstream from the barrier would increase, and the amount of tritium lost to leaks or that will be removed by a tritium capture system would increase as a result. 




Figure 4. Schematic of NGNP using a High Temperature Steam Electrolysis (HTSE) process.

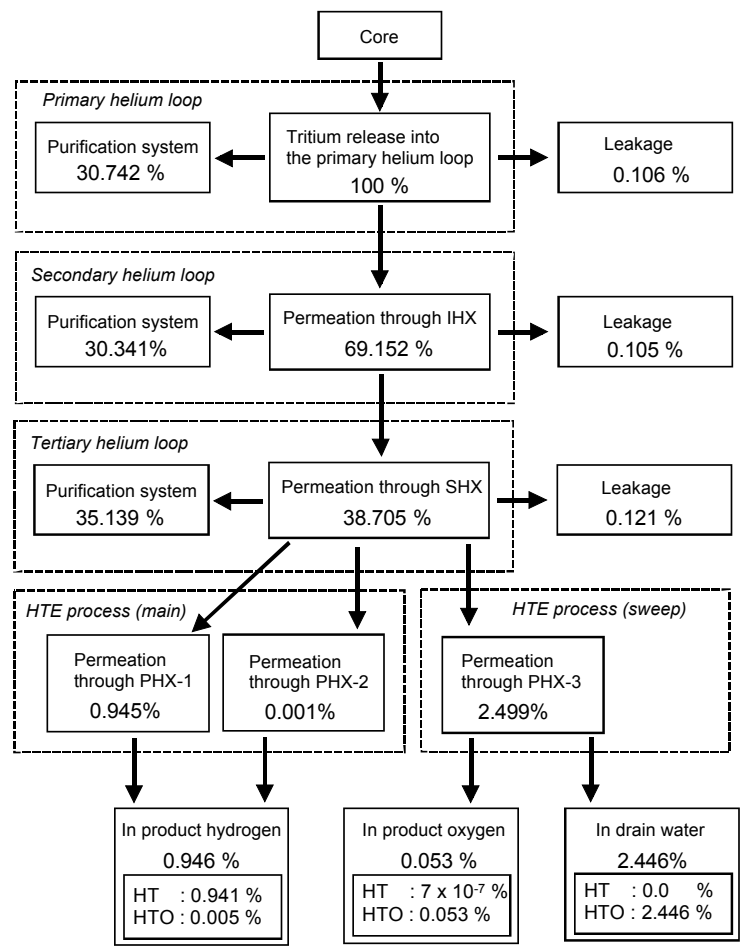

Figure 5. Tritium material balance for NGNP using HTSE process. 


\subsection{Barriers, Separation Systems, and Mitigation Measures}

A barrier is a material, coating, or surface layer that is employed in a heat exchanger in order to reduce the permeation of tritium through the heat exchanger. The barrier must still allow for the efficient transfer of thermal energy while reducing the flux of tritium through the heat exchanger surfaces. Barriers are discussed in detail in Section 2.

As was mentioned in Section 1.2.4, deployment of barriers alone is insufficient to control tritium, and effective tritium separation and removal systems are needed to balance tritium generation in the nuclear core. Separation and removal systems are, in effect, the opposite of barriers, and deploy materials that are permeable to tritium, and serve as sinks for tritium, so that captured tritium is not re-introduced into heat transfer fluid streams. Tritium separation and removal systems are discussed in Section 3.

Mitigation measures are operational steps taken to reduce the permeability of tritium through heat exchangers. One possible mitigation measure is the injection of hydrogen into coolant streams in order to create a counter-diffusion condition, which can reduce the flux of tritium through heat exchanger surfaces. This mitigation measures are discussed in Section 4. 
16 of 60 


\section{TRITIUM BARRIERS}

A tritium barrier is a material that is applied or created on a surface of a base structural material that has lower tritium permeability than the base material at the same physical conditions of interest. A barrier may also be created by the complete substitution of a base structural material with another material having lower intrinsic tritium permeability. In the NGNP, barrier materials will be needed in the high temperature heat exchangers used to transmit thermal energy from the nuclear plant to a downstream user of high temperature heat in order to reduce the potential for excess tritium contamination in the downstream plant.

The need for tritium barrier materials in the high-temperature heat exchangers of the NGNP is illustrated in the NGNP tritium migration study performed by Ohashi and Sherman [2]. In this study, the tritium distribution in an NGNP consisting of a $600 \mathrm{MWt}$ high-temperature gas-cooled nuclear reactor and a nuclear hydrogen production plant was analyzed, and various factors were altered parametrically in order to understand their effects on the calculated tritium concentration in the hydrogen product and other parts of the nuclear reactor/hydrogen plant system. Three heat exchangers were assumed for the high-temperature heat transfer system between the nuclear plant and the downstream hydrogen plant - a primary intermediate heat exchanger (IHX), a secondary intermediate heat exchanger (SHX), and a process heat exchanger (PHX). According to the study, the base material proposed for use in heat exchangers for the NGNP, Alloy 617, has a sufficiently high tritium permeability above $800^{\circ} \mathrm{C}$ that hydrogen produced by either a high-temperature steam electrolysis (HTSE) plant or by a Sulfur-Iodine (SI) plant will likely contain tritium in excess of NRC ALARA limits unless tritium barrier materials are deployed in the heat exchangers. Figure 6 shows the calculated tritium concentration in the hydrogen produced by the HTSE plant. The THYTAN model was used to perform the calculation. In the study, the source term of tritium was assumed to scale according to the source term of Fort St. Vrain, and no reduction in the amount of tritium delivered to the downstream systems was taken due to uptake or retention of tritium by graphite in the nuclear core materials. 


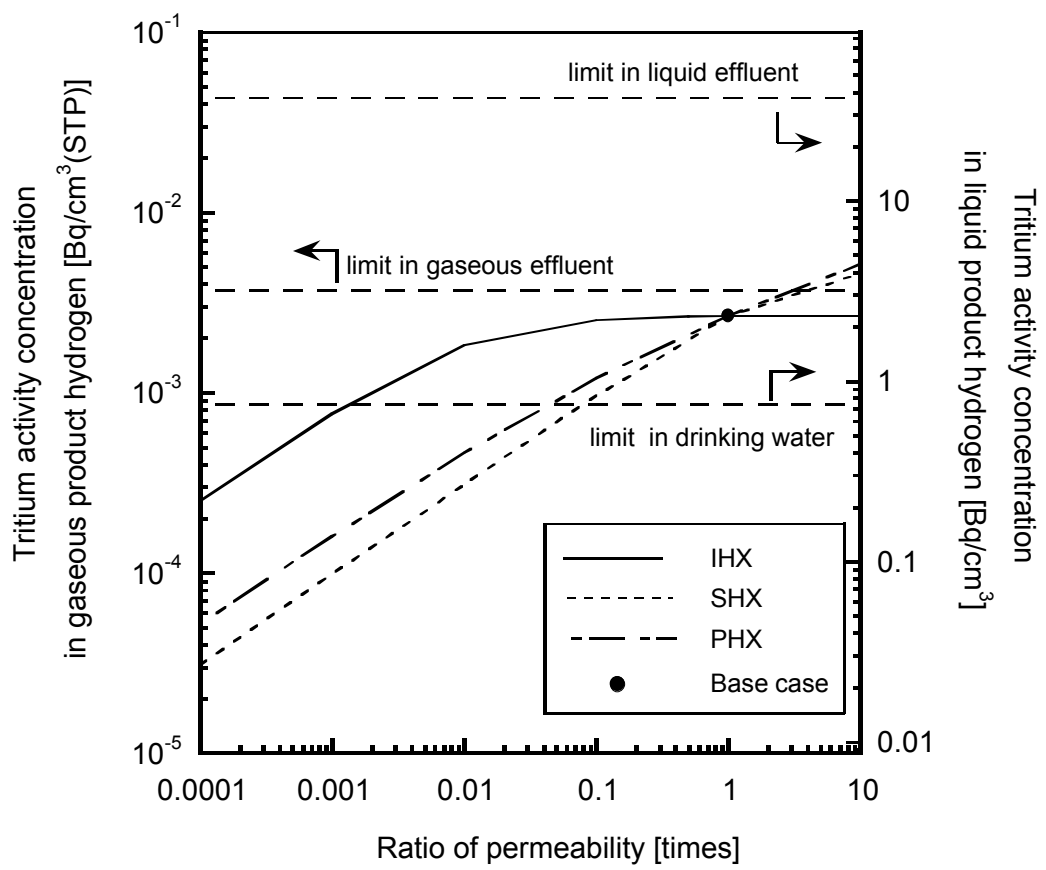

Figure 6. Tritium concentration in the product hydrogen as a function of the ratio of heat exchanger tritium permeability to the base metal tritium permeability for an NGNP employing HTSE, as calculated by THYTAN.

In the base case, the tritium concentration in the hydrogen product is approximately $1.5 \times 10^{-3}$ $\mathrm{Bq} / \mathrm{ml}$ in the gaseous form at STP, and this value is about the same as the NRC ALARA limit for tritium in air (See Table 2) with no safety margin. If the permeability of the process heat exchanger could be reduced by using a tritium barrier, as indicated by a ratio of permeability less than 1 , then the tritium concentration in the hydrogen product might be reduced to well below the ALARA limit.

For the Sulfur-Iodine process, the situation is more severe because it uses a larger proportion of its energy input as high temperature heat, and a larger high-temperature heat exchanger is needed to produce the same amount of hydrogen. With a larger heat exchanger, there is more surface area through which tritium can permeate, and tritium contamination of the hydrogen product in excess of the ALARA limit is more likely. Figures 7 and 8 show the effects of varying separately the tritium permeability of the process heat exchanger (PHX) and the secondary heat exchanger (SHX) on the concentration of tritium in the hydrogen produced by the Sulfur-Iodine process. 


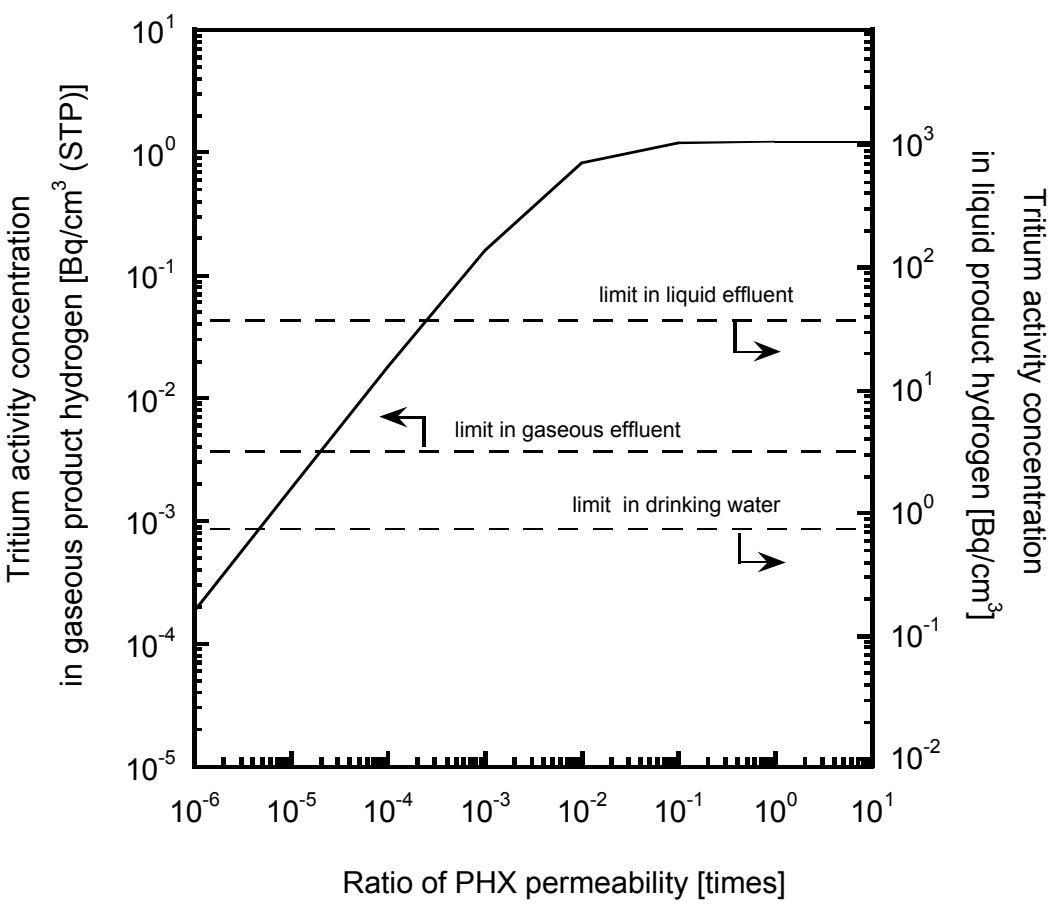

Figure 7. Tritium concentration in the hydrogen product from a Sulfur-Iodine hydrogen plant powered by the NGNP as a function of the PHX tritium permeability.

In Figure 7, the tritium concentration in the hydrogen produced in the base case is about $1 \mathrm{~Bq} / \mathrm{ml}$, which exceeds the ALARA limit by a factor of almost 700. If the permeability of the PHX were reduced by a factor of $10^{6}$, however, the limit might be achieved.

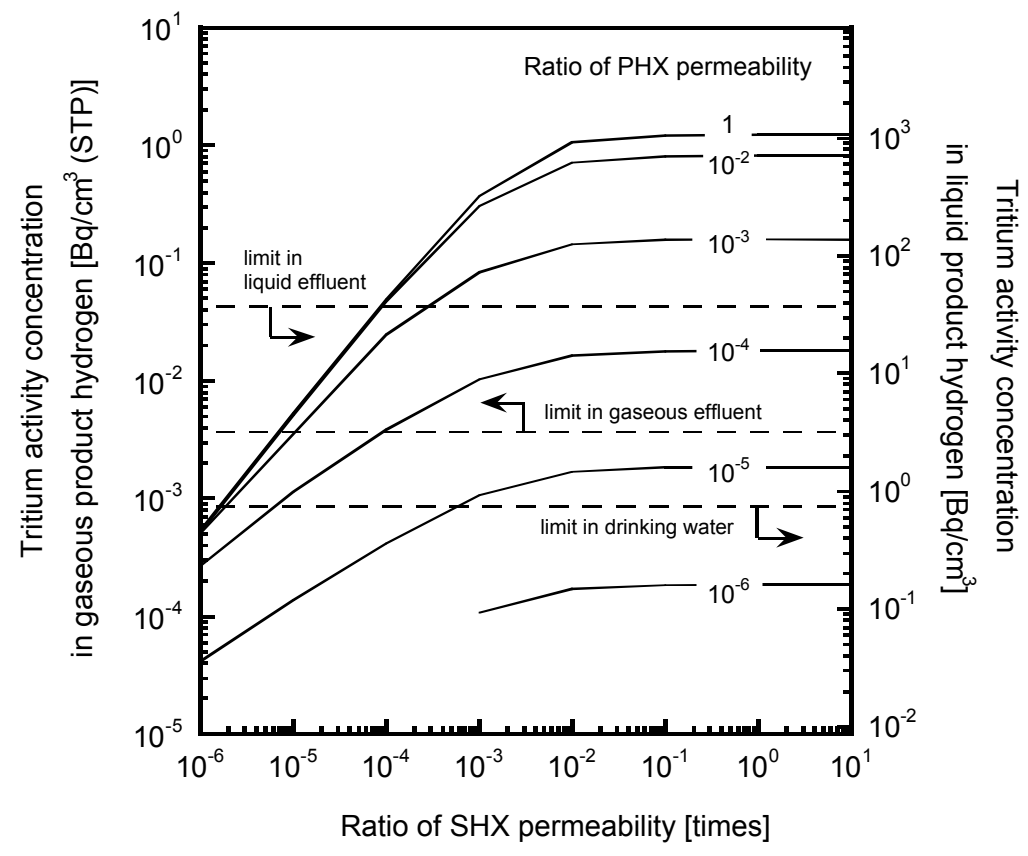

Figure 8. Tritium concentration in the hydrogen product from a Sulfur-Iodine hydrogen plant powered by the NGNP as a function of the SHX tritium permeability. 
A similar effect would be seen if a tritium barrier material were used for the SHX (see Figure 8). In the base case, the permeability of the SHX is assumed to be the same as for the PHX, and the resulting tritium concentration level in the hydrogen product is about $1 \mathrm{~Bq} / \mathrm{ml}$. If the permeability of the SHX were reduced by a factor of $10^{5}$, all other factors being equal to the base case, then perhaps the ALARA limit could be achieved.

In a heat exchanger, tritium barrier materials may be applied or bonded to the surface of the base material, or they may be created on the surface of the base material by chemical reaction of the base material with reactants in the fluid streams. Barriers can be created on the "hot" and "cold" side of the heat exchanger also, as needed, to reduce tritium permeation. In some cases, a material having much lower tritium permeability (e.g., dense $\mathrm{SiC}$ ) may be substituted altogether for the base material in order to reduce the potential for tritium permeation.

\subsection{Externally Applied Barriers}

Externally applied ceramic materials on steel substrates have been examined as tritium barriers in nuclear fusion reactors. Nuclear fusion reactors contain much larger amounts of tritium per MW generated than the NGNP will likely generate in one year, and so containment of tritium in such systems is paramount to the safety and efficiency of the fusion reactor system [32, 33]. Successfully tested surface materials include $\mathrm{Al}_{2} \mathrm{O}_{3}, \mathrm{Cr}_{2} \mathrm{O}_{3} / \mathrm{SiO}_{2}$, and layered TiN/TiC with $\mathrm{SiO}_{2}$. Such materials have been shown to reduce the permeability of hydrogen (and hydrogen isotopes) by factors of 10 to over 10,000 compared to either bare steel or steel coated with Pd to prevent surface oxidation of the material. The effectiveness of the barrier depends upon the thickness of the barrier material, the presence of defects in the barrier (pores, cracks), the fracture toughness of the barrier, thermal expansion differences between the barrier and the underlying material, and the operating history of the barrier in regard to past thermal shocks or other mechanical disturbances. The effectiveness of the barrier is also affected by the system temperature and hydrogen partial pressure. In some barrier/substrate combinations, the surface chemistry may be manipulated to allow in-situ healing of barrier defects. Some of the work performed on the leading barrier materials for fusion reactors is described below.

\subsubsection{Alumina}

Forcey et al. [34] measured the permeation of hydrogen through 316L and 1.4914 martensitic steels that had been aluminized to create a surface layer of iron-aluminum alloy or iron-aluminum intermetallic compound (aluminide) on the surface of planar and tubular samples. The commercial aluminization process called "pack-aluminizing" was used to create the layers of aluminide on the sample surfaces. In pack-aluminizing, the component to be coated is placed into an airtight retort containing a pack or mixture of powders. The powder formulas are usually proprietary but are known to contain aluminum or aluminum alloy, alumina, and a small amount of halide activator such as ammonium chloride. Air is excluded from the retort and the system is heated to $800-1050^{\circ} \mathrm{C}$. The halide activator reacts with the aluminum powder to form an aluminum halide vapor $\left(\mathrm{AlCl}_{3}\right.$ or $\left.\mathrm{AlI}_{3}\right)$, which diffuses to the surface of the component and decomposes to deposit aluminum on the component's exposed surfaces. At retort temperatures, aluminum is mobile and diffuses into the base material, which results in the formation of aluminide. Aluminide layers between 125-1000 $\mu \mathrm{m}$ are commonly applied to steels in order to create corrosion barriers in chemical plant applications, while aluminide layers placed on turbine 
blades are usually less than $50 \mu \mathrm{m}$. The exposed surface of the aluminide layer is readily oxidized by air or oxidizing impurities to form a corrosion-resistant layer of alumina $\left(\mathrm{Al}_{2} \mathrm{O}_{3}\right)$.

In the work of Forcey et al., discs having aluminide layers between 17.5-44 $\mu \mathrm{m}$ thick and tubes having aluminide layers between $225-330 \mu \mathrm{m}$ thick were placed into a test cell that allowed one side of the sample to be pressurized up to $10^{6} \mathrm{~Pa}$ while the other side of the sample was evacuated. Hydrogen and deuterium were used as test gases, and the test cell could be heated up to $600^{\circ} \mathrm{C}$. The permeation rate of hydrogen or deuterium through the sample was determined by either measuring the pressure rise in the evacuated side of the test cell over time, or by integration of gas concentration data obtained from the evacuated side of the test cell over time. A permeation reduction factor (PRF) was deduced from the data by comparing the permeation rate in the treated samples to untreated samples. According to the data, application of the aluminide layer to the discs resulted in a two orders-of-magnitude reduction in the permeability at the lowest temperature investigated, $250^{\circ} \mathrm{C}$. At higher temperatures, $400-600^{\circ} \mathrm{C}$, three to four orders reduction in permeability was achieved. For the tubes, the performance was less. At $300^{\circ} \mathrm{C}$, the reduction in permeability was about a factor of 3 to 5 , while at higher temperatures, $400-600^{\circ} \mathrm{C}$, the reduction in permeability was approximately two orders of magnitude.

A series of permeation measurements obtained at $500^{\circ} \mathrm{C}$ and at hydrogen pressures between $10^{3}$ and $10^{6} \mathrm{~Pa}$ revealed that the pressure dependence of the permeability scaled to the 0.5 power, indicating that the permeation of hydrogen in the samples was bulk-limited rather than surfacelimited (see Equation 8).

Surface analyses of the samples after testing was completed showed that the aluminide layer created on the surface of the samples had been oxidized during testing, and that $\mathrm{Al}_{2} \mathrm{O}_{3}$ layers had formed on the exposed surfaces up to $1.4 \mu \mathrm{m}$ in thickness. In some samples, a relatively thicker layer of alumina and metallic iron was found beneath the pure alumina outer layer. A timepermeation rate test performed during the work showed that the oxide layer forms in less than 24 hours after initial exposure, and it is the oxide layer that is most responsible for the reduction in the permeability as compared to bare or freshly aluminized steel.

Mechanical testing of aluminized samples showed that the coatings were subject to cracking under conditions of mechanical strain (e.g., bending, stretching, compression), but were fairly resistant to damage due to thermal cycling, at least under the conditions tested. Thinner coatings are believed to resist damage due to mechanical strain more readily than thicker coatings, but it is more difficult to apply a thin coating in a uniform manner to a large component, and so thicker coatings are applied on average in order to ensure an adequate coating on all areas of the component.

Gilbert et al. [35] examined the permeation and mechanical properties of aluminized 316 stainless steel at $330^{\circ} \mathrm{C}$ and a pressure of $2250 \mathrm{psig}$. Permeation reduction factors of $10^{2}$ to $10^{4}$ were measured, with the higher permeation reduction factors correlated with thicker coatings and increasing aluminum content of the layer. The quality of the surface layer was also observed to be a very important factor, and defects in the layer were found to greatly reduce the effectiveness of the barrier. In one sample, a defective coating provided a permeation reduction factor of 20 , while another sample of the same configuration employing a coating of high uniformity provided a permeation reduction factor of 2700 .

Hollenberg et al. [36] provides an excellent overview of several permeation studies performed with aluminized materials, including those listed above, and provides some additional insights into the permeation mechanisms in these materials, and reiterates that the resistance to 
hydrogen permeation is related to the presence of surface defects in the coating. At lower pressures, a surface-limiting phenomenon may control the permeation rate, and the exponent on Equation 8 will tend towards a value of 1 . At higher pressures, an area-defect model is more applicable, where the number and size of defects in the layer control access to the material underneath, and the exponent for Equation 8 tends towards 0.5, as was observed by Forcey et al. Also mentioned in this study are other methods of aluminizing a component, which include dipping the component in molten aluminum, flame spraying, vacuum plasma spraying, ion implantation, chemical vapor deposition, and precipitation from molten metal. With these other techniques, the component is then heat treated in order to drive the applied aluminum into the metal surface, which reacts with the substrate to create an aluminide layer.

Korinko et al. [37, 38] describes an alternative process for creating the aluminide coating called slurry coating, which may be more appropriate for components whose geometries make it difficult to create a uniform aluminide layer using pack aluminization techniques. Using this technique, a slurry containing aluminum or aluminum compounds and additives is painted or sprayed onto the surface being treated. The component is then cured below $650^{\circ} \mathrm{C}$, which is below the melting point of pure aluminum, $660.3^{\circ} \mathrm{C}$, for a period of time in order to drive off the binder materials and form a bonded layer on the surface of the component being treated. The component is then heat treated above $800^{\circ} \mathrm{C}$ in order to melt the applied aluminum and create the aluminide layer, as is done with pack aluminization. There are two variations in the slurry aluminization process - a vapor phase method, and a liquid phase method. In the vapor phase method, halide activators are included in the slurry to the same effect as in pack aluminization. In the liquid phase method, halide activators are not used and binders are added instead in order to create an adhering layer strong enough to resist cracking and spallation during handling until the heat treatment process can be accomplished, at which time the binder evaporates. Under preferred coating conditions, the final thickness of the coating is not dependent upon the thickness of slurry painted or sprayed on the surface prior to heat treatment. For their particular application and chosen aluminization vendor, Korinko et al. observed that the liquid phase method provided a smoother coating than the vapor phase method, and that the liquid phase method provided a grain orientation more favorable to prevent fatigue cracking under cyclic loading than the vapor phase method.

Korinko et al. [38] observed that aluminide coatings have self-healing capabilities if the outer alumina layer is damaged. Assuming the damage does not penetrate through the aluminide layer into the base material, then it is possible for the exposed aluminide material beneath the damaged area to become oxidized, and thus reform an alumina surface layer.

Aluminide coatings can also be created on substrates other than steels, most notably hightemperature nickel-based superalloys (e.g., Hastelloy). U.S. Patent 5,366,765 describes a slurry process used for creating aluminide corrosion barriers on nickel super alloys [39]. Instead of iron-aluminum compounds in the aluminide layer, $\mathrm{NiAl}$ is the predominant component, and the formation of an alumina surface layer is still responsible for the corrosion resistance of aluminized superalloy components. Aluminum can also form intermetallics with alloying components, including $\mathrm{Co}, \mathrm{Cr}$, Ti, and refractory metals such as $\mathrm{Ta}, \mathrm{Mo}$, and $\mathrm{W}$. The slurries used for high-nickel alloys may contain chromium [40] as an alloying agent between the nickel or cobalt rich substrate and the aluminum. The most common application for aluminide coatings on nickel superalloys are for the manufacture of gas turbines. 


\subsection{2 $\quad \mathrm{Cr}_{2} \mathrm{O}_{3} / \mathrm{SiO}_{2}$ with $\mathrm{CrPO}_{4}$}

Nakamichi et al. [41] describes a coating comprised of $\mathrm{Cr}_{2} \mathrm{O}_{3}, \mathrm{SiO}_{2}$, and $\mathrm{CrPO}_{4}$, which they call a "Chemical Densified Coating", (CDC). This coating material, when applied to 316 stainless steel, provides a suitable tritium permeation barrier that may provide a permeation reduction factor up to 1,000 at $600^{\circ} \mathrm{C}$ compared to the bare material. According to the developers, $\mathrm{Cr}_{2} \mathrm{O}_{3} / \mathrm{SiO}_{2}$ forms the basic structure of the coating, and amorphous $\mathrm{CrPO}_{4}$ is added to fill in the pores of the structure, which makes the coating stronger and more permeation resistant than a $\mathrm{Cr}_{2} \mathrm{O}_{3} / \mathrm{SiO}_{2}$ coating applied without any pore-filling component. By comparison, non-densified $\mathrm{Cr}_{2} \mathrm{O}_{3} / \mathrm{SiO}_{2}$ coatings had a measured permeation reduction factor of approximately 50 .

In addition to permeation testing, thermal shock testing was performed on coated samples by water quenching samples from a starting temperature of 400 or $600^{\circ} \mathrm{C}$ for up to $30 \mathrm{cycles}$, and it was found that such coatings having thicknesses at least up to $200 \mu \mathrm{m}$ are able to resist cracking or spalling. By comparison, non-densified $\mathrm{Cr}_{2} \mathrm{O}_{3} / \mathrm{SiO}_{2}$ coatings did not survive 30 quench cycles if their thickness exceeded $80 \mu \mathrm{m}$.

The base $\mathrm{Cr}_{2} \mathrm{O}_{3} / \mathrm{SiO}_{2}$ coating was created by painting the surface of test samples with a slurry composed of $\mathrm{CrO}_{3}, \mathrm{SiO}_{2}$, and $\mathrm{H}_{2} \mathrm{O}$, and then heating the samples up to $450^{\circ} \mathrm{C}$ using a specific time/temperature profile. Then, the densifying additive $\mathrm{CrPO}_{4}$ is added to the surface by a multistep process involving repeated exposure-and-heating cycles using a $\mathrm{CrO}_{3} / \mathrm{H}_{2} \mathrm{O}$ solution and then a $\mathrm{CrPO}_{4} / \mathrm{H}_{2} \mathrm{O}$ solution.

This manufacturing process is offered as an alternative to the aluminization processes because it uses temperatures no higher than $450^{\circ} \mathrm{C}$ to form the barrier coating. Aluminization processes require temperatures between $800-1050^{\circ} \mathrm{C}$ to complete the coating process, and in some cases, this may cause manufacturing problems due to differences in thermal expansion or the use of certain heat treatments of the base material that might be altered by the high-temperature step of the aluminization process.

\subsection{3 $\underline{\mathrm{TiN} / \mathrm{TiC} \text { with } \mathrm{SiO}_{2}}$}

Yao et al. [42] describes coatings composed of successive layers of TiN/TiC/TiN or $\mathrm{TiN} / \mathrm{TiC} / \mathrm{SiO}_{2}$ on a base material of $316 \mathrm{~L}$ stainless steel. The coating was applied using a hollow cathode deposition process. The coatings were observed to be $2-3 \mu \mathrm{m}$ thick and were found to be compact, oxidation-resistant, and did not spall below $500^{\circ} \mathrm{C}$. The permeability of tritium through samples coated with the experimental coatings and naturally oxidized stainless steel was measured, and was compared to the permeability of tritium through Pd-coated stainless steel as a reference in order to determine permeability reduction factors. The measured permeability reduction factors of the coatings and those measured for naturally oxidized stainless steel are shown in Table 3.

Table 3. Measured Permeation Reduction Factors from Yao et al.

\begin{tabular}{|c|c|c|}
\hline & $200-500^{\circ} \mathrm{C}$ & $500-600^{\circ} \mathrm{C}$ \\
\hline Natural Oxidation & $10^{2}$ to $10^{3}$ & \\
\hline TiN/TiC/TiN & $10^{4}$ to $10^{5}$ & $10^{3}$ to $10^{4}$ \\
\hline $\mathrm{TiN} / \mathrm{TiC} / \mathrm{SiO}_{2}$ & $10^{4}$ to $10^{6}$ & $10^{3}$ to $10^{4}$ \\
\hline
\end{tabular}


Tritium permeability of the coatings above $600^{\circ} \mathrm{C}$ could not be obtained because the coatings were partially destroyed above that temperature due to spallation and cracking of the applied coatings. These coating methods are often line-of-sight methods and are less accommodating for complex shapes.

\subsection{In-Situ Barriers}

In Section 2.1.3, it was briefly mentioned that a natural oxide coating can provide a reduction in tritium permeability in comparison to bare metal or metal coated with Pd to prevent surface oxidation. If the oxidation processes are controlled, material corrosion processes might be employed to create oxidation surface layers that are even more effective than layers created by natural oxidation processes. Such coatings are referred to here as in-situ coatings because they can be created after the heat exchanger or other component has been installed. Bruckhemer et al. [43] performed extensive studies of oxide coatings on high-temperature alloys, including the high-nickel and chromium alloys Inconel $617(0.7 \% \mathrm{C}, 22 \% \mathrm{Cr}, 12.5 \% \mathrm{Co}, 1 \% \mathrm{Al}, 9 \% \mathrm{Mo}$, $54.8 \% \mathrm{Ni})$ and Incoloy $800 \mathrm{H}(0.08 \% \mathrm{C}, 0.75 \% \mathrm{Mn}, 0.5 \% \mathrm{Si}, 21 \% \mathrm{Cr}, 32.5 \% \mathrm{Ni}, 0.4 \% \mathrm{Ti}, 0.4 \%$ $\mathrm{Al}, 44.37 \% \mathrm{Fe}$ ). Tritium permeation reduction factors were measured for oxidized material between approximately 200 and 1000, with the higher permeation reduction factors associated with higher temperatures.

According to Bruckhemer et al., the composition and morphology of the barrier material depends upon the temperature, oxidizing potential of the surrounding atmosphere, and the past history of the layer. In Alloy 800, which contains iron and chromium, initial oxidation of a clean metallic surface leads to the creation of a surface layer having a spinel structure (i.e., of the form $\mathrm{XY}_{2} \mathrm{O}_{4}$, where $\mathrm{X}$ and $\mathrm{Y}$ are $\mathrm{Fe}$ and $\mathrm{Cr}$ ) and is composed of chromium oxide, iron oxide, and metal oxide impurities. The initial barrier provides little resistance to tritium permeation. If the initial layer is exposed to an atmosphere with a reduced oxidation potential at high temperature, the composition and morphology of the layer changes due to migration of additional chromium from the substrate to form a denser surface layer that is composed mostly of $\mathrm{Cr}_{2} \mathrm{O}_{3}$ with less spinel present. Once the denser layer forms, it is much more stable mechanically than the mixed metal oxide layer and provides much better performance as a barrier material. In addition, the dense layer remains stable over a wide range of oxidizing potentials. Alloy 800 was used in some heat exchanger components of the German Advanced Very High Temperature Reactor (AVR).

The surface layer, being a ceramic, is brittle and can fracture in response to thermal stress. Thermal stresses created mechanical strains in the surface layer due to the mismatch in thermal expansion coefficients between the surface layer and the base material, and mechanical fracture of the surface layer can result. Oxidized samples were exposed to differing cooling cycles between the targeted operating temperature of the barrier materials, $950^{\circ} \mathrm{C}$, and room temperature. Microcracking was observed in the temperature range between $650^{\circ} \mathrm{C}>\mathrm{T}>\mathrm{RT}$, with peak cracking witnessed at $200^{\circ} \mathrm{C}$. A delayed and reversible cracking effect was seen at room temperature also, which was attributed to a phase transformation of the spinels. Macrocracking was also witnessed, but was correlated with higher oxidation potentials and materials having higher iron content. Cracking of the surface layer, either due to microcracking or macrocracking, causes a severe reduction in barrier performance. Such cracking is expected to occur whenever the oxidized surfaces must be cycled in temperature such as would occur during shutdowns or process upsets. 
Fortunately, the oxide layers are self-healing, and can be re-established after a temperature cycle has occurred by the same mechanisms that created the barrier layer upon initial exposure, and full barrier function can be restored in time. Samples characterized as having $10 \%$ damage, $50 \%$ damage, and 100\% damage were reheated and exposed to oxidative atmospheres, and the tritium permeability of the samples was measured over time. Full layer performance could be restored within 2-5 days. Self-healing barriers may be subject to a limiting life if excessive spallation and re-growth occur since the active species in the alloy can be depleted below critical quantities needed for oxide development.

Fütterer et al. [33] also examined in-situ barrier coatings formed by oxidation. Fütterer et al. sites sources that believe the oxidation barrier layer that forms on Alloy 800 is composed of $\mathrm{MnCrO}_{4}$ spinel or even non-spinel $\mathrm{Fe}_{3} \mathrm{O}_{4}$, which is different than what Bruckhemer et al. had observed. Consistent with Bruckhemer et al., however, were the findings that oxidation of the surface must be carried out in a controlled manner, and uncontrolled oxidation of Alloy 800 surfaces exposed to steam in a steam generator provided almost no barrier to tritium permeation. Steam pressure and temperature conditions are provided that can be used to create barrier layers on Alloy 800. The barrier materials thus created are self-healing, and can be restored to full function after stress-induced damage by once again controlling the steam conditions to re-create a stable oxidation barrier.

The NGNP is most likely to select Inconel 617 as a high-temperature heat exchanger material, and it does not contain $\mathrm{Mn}$ nor $\mathrm{Fe}$, and so will form only $\mathrm{Cr}_{2} \mathrm{O}_{3}$ as a significant corrosion layer on oxidized surfaces. Therefore, the barrier layers created on Inconel 617 surfaces should tend towards the higher end of performance stated by Bruckhemer et al., as such layers will be composed of dense $\mathrm{Cr}_{2} \mathrm{O}_{3}$. Surface analyses will be needed to determine if this hypothesis is true, and to find out whether a dense layer forms immediately upon oxidation, or whether specific oxidizing conditions are needed to establish a barrier layer.

There are upper temperature limits, however, where a dense $\mathrm{Cr}_{2} \mathrm{O}_{3}$ layer may no longer be effective. Wright [44] indicates that $\mathrm{Cr}_{2} \mathrm{O}_{3}$ becomes a volatile corrosion product above $950^{\circ} \mathrm{C}$, and thus it becomes more difficult to maintain a dense barrier unless a constant supply of oxidant (e.g., $\mathrm{O}_{2}, \mathrm{H}_{2} \mathrm{O}$ ) is available in the gas stream, which may serve to regenerate the layer as fast as it is lost to volatilization. While continuous oxidation of the surface to regenerate the tritium barrier is beneficial for keeping a barrier in place, volatilization of $\mathrm{Cr}_{2} \mathrm{O}_{3}$ is a corrosion mechanism that can eventually lead to thinning and premature failure of the underlying surface.

\subsubsection{Solid Ceramic Barriers}

Hollenberg et al. [36] provides data on the permeability of hydrogen through several ceramic materials, and these data are copied below in Figure 9. As can be seen in the graph, the permeability of hydrogen through solid ceramic materials is many orders of magnitude below the untreated metal. 


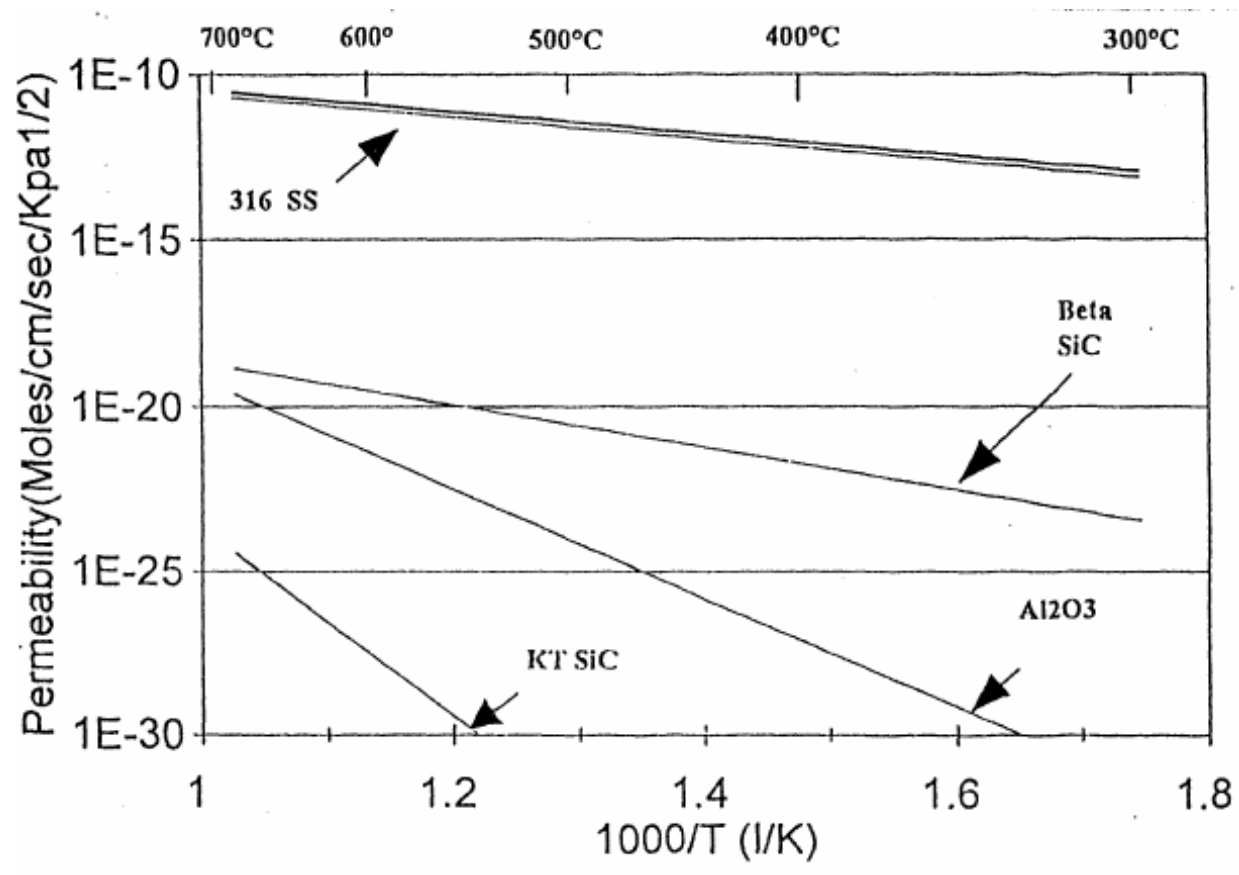

Figure 9. Comparison of hydrogen permeabilities of stainless steel to various ceramics.

In Figure 9, beta-phase $\mathrm{SiC}$ provides the worst performance at increasing temperatures, while $\mathrm{Al}_{2} \mathrm{O}_{3}$ and $\mathrm{KT} \mathrm{SiC}$ provide much better performance. Still, these performance scales are relative, and even beta phase $\mathrm{SiC}$ provides a $10^{7}$ to $10^{8}$ reduction in permeability at $700^{\circ} \mathrm{C}$ in comparison to the permeability of $316 \mathrm{SS}$ at the same temperature. The permeabilities shown in the figure were measured using bulk material and were not measured as a surface coating on a metal substrate.

Solid ceramic materials, having no substrate material from which to regenerate damaged areas, have no self-healing capability.

\subsection{Applications to NGNP}

The NGNP will be expected to operate with an outlet temperature of $850-900^{\circ} \mathrm{C}$ and will generate tritium, as was discussed in Section 1.2. With one of the primary missions of the NGNP being a generator of high-temperature heat for downstream users, tritium barriers will be needed in the intermediate heat transfer loops. Multiple barrier materials could be used, but the best choice of barrier material will have the following characteristics: permeation reduction factors of $10^{3}$ or greater at the highest temperatures of interest, and self-healing capability if the barrier material is subject to damage from temperature cycling.

At first glance, solid ceramic materials such as $\mathrm{SiC}$ would appear to provide the best barrier materials for use in the NGNP. They have a much reduced permeability to hydrogen even compared to ceramic-coated metals, and their heat transfer characteristics are well known. If ceramic heat exchangers could be used for one or more heat exchangers in the intermediate heat transfer loop, then it would appear that their superior tritium barrier capabilities would essentially eliminate the potential for downstream tritium contamination in the intermediate loop. The data are incomplete on ceramic heat exchangers, however, and it is unknown how various ceramics 
and heat exchanger designs would perform after repeated temperature cycling. Without selfhealing capabilities, heat exchanger designers would have to rely on the toughness of various ceramics to avoid cumulative damage due to hairline cracks, which could lead eventually to leaks through heat exchanger surfaces and by-passing of the barrier. Also, the ability to construct large ceramic heat exchangers on the MW-scale has not yet been demonstrated, and ceramic heat exchangers for nuclear applications are not yet recognized in the ASME code. Ceramic heat exchangers have much potential to eliminate downstream tritium contamination and deserve further examination by the NGNP Project.

A ceramic heat exchanger is being developed by the DOE Nuclear Hydrogen Initiative (NHI) to provide thermal energy to one of two thermochemical hydrogen production processes - the Sulfur-Iodine process or the Hybrid Sulfur process. The decomposition reaction is endothermic and operates best at higher temperatures, $750-800^{\circ} \mathrm{C}$, and therefore the decomposer must operate both as a heat exchanger and as a chemical reactor. The severely corrosive conditions of the decomposer require the use of ceramic materials, since metallic materials are known to corrode quickly at the decomposition conditions. Sandia National Laboratories has developed a candidate decomposer design that uses a bayonet composed of concentric SiC tubes (see Figure 10), and this has been shown to operate very well as a decomposer and as a heat exchanger. The design has yet to be demonstrated using gas heating and at larger scales. If deployed for a large hydrogen plant, a heat exchanger/decomposer based upon this prototype should greatly reduce the potential for downstream tritium contamination in a Sulfur-Iodine or Hybrid Sulfur hydrogen production process.

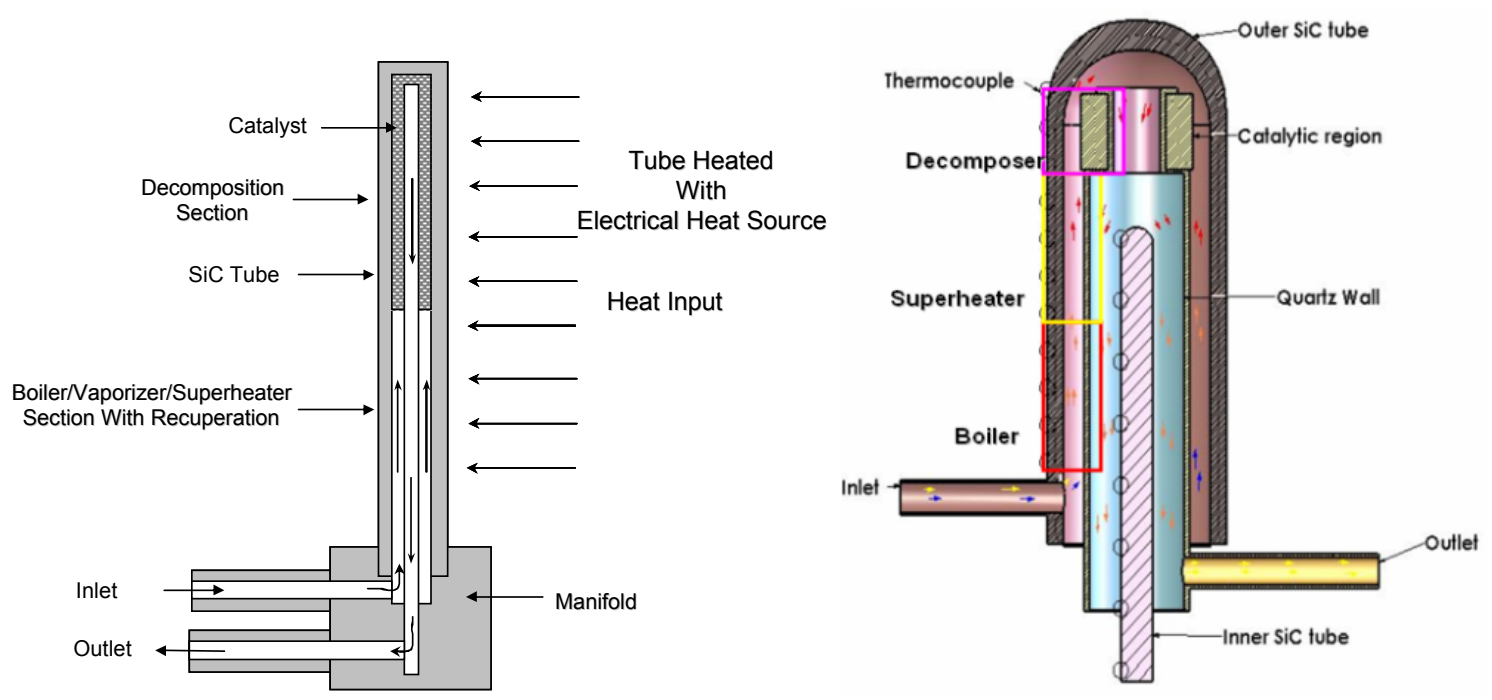

Figure 10. Drawings of the Sandia SiC Sulfuric Acid Decomposer.

For applications that require the use of metallic heat exchangers, barrier coatings with the capability to self-heal would be the most suitable. In this category, oxide coatings created in-situ would be the easiest to create and maintain. Intermediate heat transfer loop fluid chemistry can be controlled by on-line systems in order to maintain slightly oxidizing conditions, which will allow oxide barriers to become established and maintain their self-healing capabilities. 
For some heat exchangers, aluminide coatings should also be considered because aluminide coatings are projected to perform better than in-situ oxide coatings, at least up to $600^{\circ} \mathrm{C}$. The tritium permeability of aluminized Alloy 617 would need to be measured up to $900^{\circ} \mathrm{C}$ in order to extend the available data. No information was found in the literature that describes the stability or aging characteristics of aluminide layers on Alloy 617 at $800-900^{\circ} \mathrm{C}$. Also, it is unknown how well the layers would adhere to the surface of Alloy 617, and whether the barrier would be selfhealing over the lifetime of the aluminized component.

The oxidizing potential for the gas must be balanced with the corrosion potential of the material. If the oxidizing potential is too low, yet oxidizing, a situation can occur which leaches out chromium without forming an oxide film and results in a loss of creep resistance [45].

The other coating materials discussed may not be suitable for the NGNP. The densified layer involving $\mathrm{Cr}_{2} \mathrm{O}_{3}, \mathrm{SiO}_{2}$, and $\mathrm{CrPO}_{4}$ is likely superfluous since a $\mathrm{Cr}_{2} \mathrm{O}_{3}$ layer can be created in-situ that has similar tritium permeation reduction capabilities without the extra effort of building up the layer during the manufacturing process. The TiC/TiN layer is mechanically unstable above $600^{\circ} \mathrm{C}$ and is not self-healing, and so is not a good candidate for the NGNP intermediate heat transfer loop heat exchangers. 


\section{SEPARATION SYSTEMS}

Tritium separation systems are the counterpart to tritium barrier materials, and may be needed to remove tritium from the intermediate heat transfer loops. Without removal of accumulating tritium, the use of tritium barriers alone on heat exchanger surfaces would reduce a migration pathway for tritium without providing an alternative outlet, and tritium would accumulate in the intermediate heat transfer loops upstream from the tritium barriers. Accumulation of tritium in the loops would cause the tritium concentration to increase in heat transfer fluids, and this would lead to increased losses of tritium to the environment through existing leaks, and may also cause a reduction in tritium barrier effectiveness due to an increasing tritium concentration gradient across the tritium barriers. Tritium separation systems provide a sink for tritium emitted from the nuclear core, and allow collection and containment of tritium that would have been otherwise lost to leaks or contamination of downstream processes. An effective tritium separation system will also enhance the performance of the tritium barriers by reducing the available inventory and concentration of tritium in the loops, thus reducing the driving force for permeation across the tritium barriers.

Many tritium separation systems consist of two parts: a permeation window, and a capture system. A permeation window is a selective barrier that allows hydrogen species such as tritium to permeate through it without allowing for the permeation of the bulk heat transfer fluid. Tritium permeates across the permeation window in response to a concentration or activity gradient. When a permeation window is incorporated into a process unit, it is sometimes referred to as a permeator. Though it may be possible to construct permeation windows that have a preferred permeation direction through the use of surface coatings, permeation windows are generally not directional, and hydrogen species can permeate in either direction in response to the concentration gradient until the driving force is equalized across the window [46]. So, in order to maintain the driving force for permeation across the permeation window in the preferred direction, a capture system is needed on the downstream side of the permeation window to retain the tritium so that it is not available to permeate back through the permeation window.

In the case where the concentration or partial pressure of tritium is very low in the fluid stream, it may be difficult to create a sufficient tritium gradient across a permeator to allow for a practical system design, and so direct capture systems involving adsorption or absorption mechanisms are employed instead.

In this section permeation window options are discussed, and then multiple tritium capture systems are described that employ chemical transformation, adsorption and absorption. Once captured, the tritium will not be reintroduced into the nuclear reactor system and must be disposed. Alternative disposal pathways are discussed.

\subsection{Tritium Permeation Windows}

\subsubsection{Permeation Window Materials}

Some of the earliest work on tritium permeation window materials was performed with pure Pd films. Snelling [46] describes an apparatus that employed a Pd film of thickness no greater 
than 0.001 inch $(25 \mu \mathrm{m})$ to separate hydrogen from a gaseous mixture. In the work, a porous earthen ware or alundum [fused alumina] backing was used to provide structural support for the film, and the film was heated to "... an elevated temperature and preferably at bright red heat..." in order to increase the permeability of hydrogen through the Pd film. The Pd film allowed the hydrogen to permeate through the membrane in response to a pressure gradient, and permeation could be maintained until the hydrogen pressure on both sides of the membrane became equal. The work also suggested that if an ongoing removal process could be performed on the downstream side of the membrane, then a continuous hydrogen removal processes could be maintained using such a membrane (i.e., hydrogen capture). The work also suggests that Pt might be used as a membrane material, but later work by Peachy et al. [47] in this area showed that Pt is much less permeable to hydrogen than is Pd by at least $10^{3}$, as shown in Figure 11.



Figure 11. Measured permeabilities of several corrosion-resistant transition metals.

The next step in the development of Pd-based hydrogen separation films occurred when it was discovered that alloying a Pd film with Ag improved its hydrogen permeability. Hunter [48] describes a Pd film alloyed with 20-40 wt \% silver, and preferably $27 \mathrm{wt} \%$ silver, that improved hydrogen permeability at $450-550^{\circ} \mathrm{C}$ by $23-72 \%$ over that of pure Pd. Hunter's tests involved PdAg films that had a thickness of 0.001 " $(25 \mu \mathrm{m})$. The film requires a porous backing material, but no specific porous backing material is recommended. 
Yamamoto and Goto [49] discuss the use of pure Pd films and describe shortcomings related to hydrogen transport of such membranes. According to Yamamoto and Goto, hydrogen absorbed by palladium forms a separate phase called $\beta$-Pd below $200^{\circ} \mathrm{C}$. $\beta$-Pd is hard and brittle, and the volume changes that occur as a result of this transition can lead to deformation and destruction of the film. At higher temperatures (e.g., $500-600^{\circ} \mathrm{C}$ ), Pd loses tensile strength, and so there is a need to thicken Pd membranes in order to maintain a coherent film at such temperatures. Thickening the film, however, reduces the permeability of the film. They suggested alloying the $\mathrm{Pd}$ with at least one element from the set $\mathrm{Cu}, \mathrm{Ag}$, or $\mathrm{Au}$ at a concentration of $2-40 \mathrm{wt} \%$, and at least one element from the set $\mathrm{Fe}, \mathrm{Co}, \mathrm{Ni}, \mathrm{Rh}, \mathrm{Ru}, \mathrm{Pt}$, Ir or Os at $0.1-20 \mathrm{wt} \%$. The suggested alloys have increased tensile strength at higher temperature versus simpler alloys composed only of Pd and $\mathrm{Ag}$ (average tensile strength $26 \mathrm{ksi}$ versus $11 \mathrm{ksi}$ at $500^{\circ} \mathrm{C}$ ), resist embrittlement due to $\beta$-Pd formation at lower temperatures, and have increased hydrogen permeability by about a factor of 2 over that of pure Pd. In addition, the alloying elements help make the films more corrosion resistant. Experiments performed to support the development of the films were performed using thin cylinders of material with no porous backing material.

A further refinement of Pd membranes is proposed by Buxbaum [50]. Buxbaum describes a composite film composed of a thin layer of $\mathrm{Pd}, \mathrm{Pd}$ alloy or Pt; a relatively thicker layer composed of a refractory metal such as $\mathrm{Ta}, \mathrm{V}$, or $\mathrm{Zr}$; and another thin layer of $\mathrm{Pd}, \mathrm{Pd}$ alloy, or Pt.

Refractory metals are used for the bulk of the membrane because of their higher strength at elevated temperature and their greater permeability to hydrogen than Pd (see Figure 10), while the thin layers of Pd, Pd alloys, or Pt are used because of their ability to catalyze hydrogen decomposition and recombination at the exposed surfaces. The refractory material provides the structural support for the permeator, and no porous backing material is needed for the membrane. The thin surface films also serve to protect the refractory base material from poisons such as carbon, oxygen, nitrogen and sulfur. A composite film is also projected to cost less than Pd- or Pt-based films because of the relatively cheaper cost of the refractory materials. To install the Pd- or Pt-based films, Buxbaum suggests electroless or electrolytic processes which can be used to apply the films onto tubular or plate surfaces that may be used in hydrogen separation devices [51].

Another extension of composite membrane technology has been pursued by Dorris et al. [52], who proposed a homogenous cermet membrane material composed of Pd or other refractory metals and a ceramic material. To manufacture the membrane, a metal powder consisting of solely $\mathrm{Pd}, \mathrm{Nb}, \mathrm{Ta}, \mathrm{V}$, or $\mathrm{Zr}$, or a binary alloy of $\mathrm{Pd}$ with one of the other metals previously listed or $\mathrm{Ag}$, is mixed with a ceramic powder consisting of $\mathrm{Al}_{2} \mathrm{O}_{3}, \mathrm{BaTiO}_{3}, \mathrm{SrTiO}_{3}, \mathrm{ZrO}_{2}$, or combinations of these powders, and is sintered at $1300-1600^{\circ} \mathrm{C}$. The composite material is nonporous, hydrogen permeable, and is more resistant to corrosion than metallic membranes. In the work, the material was sintered into discs having a thickness of $0.025 \mathrm{~mm}$ to $1.25 \mathrm{~mm}$, and the permeability of the discs was measured. The permeation rate of hydrogen through samples was measured to be between $0.12 \mathrm{~cm}^{3} \mathrm{~min}^{-1} \mathrm{~cm}^{-2}$ at $500^{\circ} \mathrm{C}$ and $6 \mathrm{~cm}^{3} \mathrm{~min}^{-1} \mathrm{~cm}^{-2}$ at $900^{\circ} \mathrm{C}$, but no data were provided on the permeation rate of hydrogen through Pd metal films under the same experimental conditions. Also, no data were provided on the pressure of hydrogen upstream of the permeation window and the intrinsic permeability of the material $(\Phi(T))$, so that a comparison could not be deduced from the data. The operating temperature of a permeation membrane prepared from the sintered material is between $250-1500^{\circ} \mathrm{C}$ and is especially appropriate for the operating range $600-1000^{\circ} \mathrm{C}$.

Pd-based membranes are the base technology choice for hydrogen permeation windows in larger projects targeted for industrial or large-scale use. The Pall Corporation, for instance, is developing a layered hydrogen separation membrane composed of a thin $\mathrm{Pd} / \mathrm{Au}$ alloy layer [53], a 
thin diffusion barrier, and a porous stainless steel backing that can be used to separate hydrogen from a gaseous mixture at $400^{\circ} \mathrm{C}$. The diffusion barrier between the membrane and the porous stainless steel backing is used to prevent diffusion of Pd and other alloying elements into the stainless steel at temperature, and may be formed by oxidation of the base material [54]. Hydrogen permeators prepared in this way can be fashioned into long tubes and arranged in tubular banks. The ITER Project has selected to use Pd-Ag membranes in their tritium separation systems, which are integral to their ability to recycle tritium in the tokamak fusion reactor plant $[55,56]$. ITER will be a 500 MWth fusion energy plant that is targeted for start-up by the end of 2016 [57].

The definition of a permeation window is somewhat dependent upon the expectations of the system designer, and other less permeable materials may serve as hydrogen separators, most notably structural engineering metals. Compared to Pd-Ag membranes, structural metals tend to have lower hydrogen permeabilities, but not drastically lower, and hydrogen can still permeate at significant rates through structural metals if the material is thin and the temperature is elevated. Table 4 shows the hydrogen permeability of Pd-Ag as compared to Ni, Incoloy 903, Inconel 718, and austentic stainless steel at $352^{\circ} \mathrm{C}$. The permeability of hydrogen through all of these materials increases with increasing temperature.

Table 4. Permeabilities of Pd-Ag Compared to Several Structural Metals

\begin{tabular}{|c|c|c|}
\hline Metal & $\begin{array}{c}\mathrm{H}_{2} \text { Permeability at } 352^{\circ} \mathrm{C} \\
\left(\mathrm{mol}_{\mathrm{H} 2} \mathrm{~m}^{-1} \mathrm{~s}^{-1} \mathrm{~Pa}^{-0.5}\right)\end{array}$ & Reference \\
\hline Pd-25Ag & $2 \times 10^{-8}$ & {$[58]$} \\
\hline Ni-201 & $0.6 \times 10^{-8}$ & {$[59]$} \\
\hline Incoloy 903 & $0.2 \times 10^{-8}$ & {$[60]$} \\
\hline Inconel 718 & $0.11 \times 10^{-8}$ & {$[60]$} \\
\hline Austenitic Stainless Steel & $0.18 \times 10^{-8}$ & {$[60]$} \\
\hline
\end{tabular}

The permeability of some of the structural materials featured is about an order of magnitude lower than Pd-25Ag, but is still high enough that the featured materials can be considered somewhat transparent to hydrogen permeation in comparison to the tritium barrier materials discussed in Section 2. Since the permeation rate is also a function of temperature, available surface area, and material thickness, the high-temperature heat exchangers envisioned for use by the NGNP are particularly vulnerable to hydrogen permeation. The NGNP's heat exchangers will employ structural metals (e.g., Inconel 617), operate at high temperature, have large surface areas, and will employ thinner materials in order to enhance heat transfer, and such configurations also increase the tendency for hydrogen (i.e., tritium) to permeate through the heat exchangers. The observations provided in Table 4 reinforce the need to utilize tritium barrier materials, as described in Section 2, and also suggests that it is possible to construct hydrogen separation devices without using Pd-based or refractory metal-based membranes, especially if the system operates at high-temperatures.

Other hydrogen separation materials have been developed including polymeric membranes, ceramic membranes, and electrolytic membranes. Organic membranes are not recommended for use above $250^{\circ} \mathrm{C}$, and so are not considered here for use with the NGNP. Also, organic membranes cannot achieve $100 \%$ selectivity for hydrogen. Ceramic membranes composed of Vycor glass, microporous $\mathrm{Al}_{2} \mathrm{O}_{3}$, or microporous glass have been shown to operate as hydrogen separators [61] for application to steam-methane reforming processes at the temperatures of interest to the NGNP, but none of these materials has $100 \%$ selectivity for hydrogen. $100 \%$ 
selectivity for hydrogen is considered a requirement for the separation of dilute tritium from a much larger concentration of heat transfer fluid, and so such membranes are not covered further here. Purely ceramic electrolytic materials have been found that are permeable to hydrogen in response to an applied voltage and that have $100 \%$ selectivity [62]. Such systems are referred to as hydrogen pumps, and have been suggested for use by some researchers in the ITER. Further developments are needed on the membrane materials in order to increase hydrogen permeability, and such hydrogen pumps are not yet ready to replace Pd-based membranes. On the encouraging side, hydrogen isotopes have differing mobilities through the membrane, and instruments capable of detecting and perhaps quantifying tritium concentrations in fluid streams may be developed based on such technologies.

\subsubsection{Contaminant Effects}

Pd-type membranes may suffer reduced hydrogen permeability from competitive adsorption or coking if $\mathrm{CO}, \mathrm{CO}_{2}, \mathrm{H}_{2} \mathrm{O}$, or organic materials such as $\mathrm{CH}_{3} \mathrm{OH}$ are present in the gas stream [63]. Components such as $\mathrm{CO}, \mathrm{CO} 2$, or $\mathrm{H}_{2} \mathrm{O}$ compete for adsorption sites on the surface of the palladium membrane and block hydrogen disassociation sites. Hou and Hughes showed that hydrogen permeance was reduced by up to $15 \%$ with increasing mole fractions of $\mathrm{CO} 2$ in the hydrogen stream being separated at a temperature of $548 \mathrm{~K}\left(275^{\circ} \mathrm{C}\right)$, while the presence of $\mathrm{CO}$ and $\mathrm{H}_{2} \mathrm{O}$ in the hydrogen stream reduced hydrogen permeance by up to 50 and $60 \%$, respectively. The competitive adsorption effect is reduced at higher temperatures, and reductions of no more than $10 \%$ were measured in the presence of $\mathrm{CO}$ at $673 \mathrm{~K}\left(400^{\circ} \mathrm{C}\right)$.

Coking is caused by the degradation of organic materials on the surface of the Pd membrane, and the presence of a carbon layer on the membrane can reduce hydrogen permeability. Coking has been observed when organic contaminants such as $\mathrm{CH}_{3} \mathrm{OH}$ (methanol) or $\mathrm{CH}_{2} \mathrm{CHCH}_{3}$ (propene) were present in the hydrogen stream in the absence of oxygen. In Jung et al. [64], it was found that the carbonaceous layer created by coking could gradually be removed by treating the membrane with pure hydrogen at $600^{\circ} \mathrm{C}$ for several hours, or more quickly at $600^{\circ} \mathrm{C}$ by injecting oxygen or steam.

\subsubsection{Permeator Shapes}

Permeation, like heat exchange, depends in part on the available surface area for permeation, and so permeation surfaces take on shapes that are similar to those used in heat exchangers, and plates or tubes can be used. Endlund [65] describes a composite permeator membrane consisting of a stable porous intermediate layer between a hydrogen-permeable coating metal layer and a rigid support matrix. Figure 12 shows some plate, square duct, and tubular concepts that were described by Endlund in U.S. Patent 5,498,278.

Clark et al. [66] describes the design of palladium-based diffusers or permeators used at the Tritium Facilities at the Savannah River Site. The diffusors employ a heated tubular Pd-25Ag tritium permeation membrane shaped into a coil. A tritium-containing gas flows through the coiled tube, and tritium permeates through the coil into an evacuated collection space. The recently started Tritium Extraction Facility at the Savannah River Site uses an alternative permeator design, but still employs the Pd-Ag coils that were used in the earlier diffuser models [67]. 

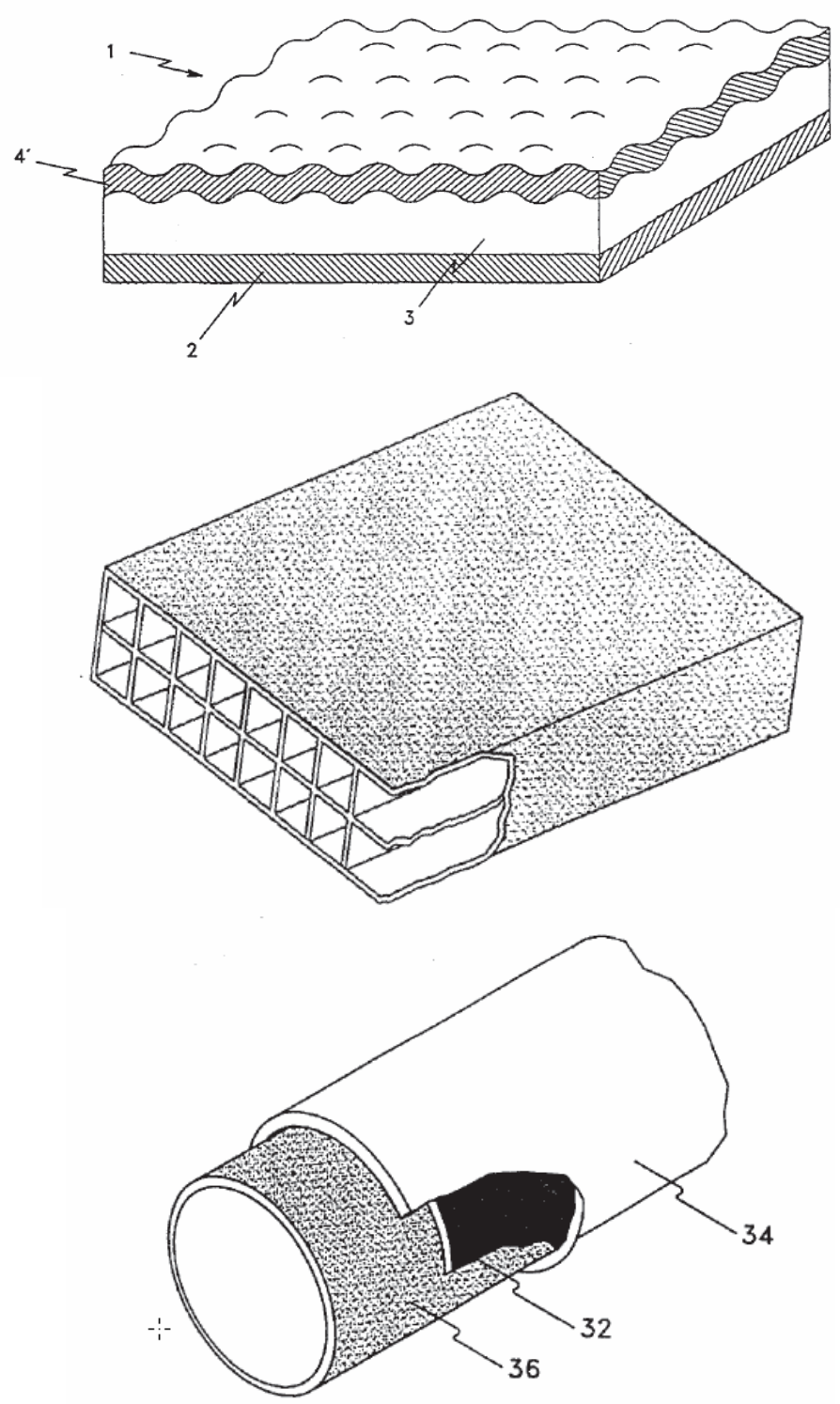

Figure 12. Plate and tubular hydrogen separation membranes described by Endlund [62].

\subsection{Capture}

Tritium capture consists of removal of tritium from a fluid stream in such a manner that it becomes unavailable for permeation back into the fluid stream. Under this definition, tritium adsorbed from a reactor coolant stream onto a fluid conduit surface and released again back into the reactor coolant stream does not constitute capture, while tritium that is removed from a reactor coolant stream through a permeator and trapped in an absorptive material does constitute capture. Capture systems may be used on the downstream side of a permeator or may be exposed 
directly to the tritium-containing fluid if the concentration of tritium in the fluid is very low and the environmental conditions of the fluid stream are favorable for use of a particular tritium capture system. Tritium capture may be accomplished by using a purge stream, flushing or evacuation of the extracted tritium on the downstream side of a permeation membrane, adsorption or absorption of tritium onto or into getter materials, or chemical transformation of the molecular tritium species into less permeable forms followed by collection or removal of the transformed tritium species. These methods are discussed in the sub-sections below.

\subsubsection{Purge Streams}

A purge stream is a bleed-off stream that is used to remove accumulated material from a cyclic fluid stream. No chemical separation is performed on the purge stream, and accumulated material is removed from a recycle stream along with bulk fluid at existing concentrations.

Removal of accumulated material, in this case tritium, is accomplished by manipulating the accumulated material's mass balance. In a closed heat transfer loop, tritium enters the loop by permeation through a heat exchanger surface and enters the bulk fluid stream in the closed cooling loop. If the inlet rate of tritium is greater than the outlet rate for tritium from downstream permeation or bulk fluid leaks, tritium will accumulate in the closed loop until the concentration of tritium climbs high enough in the closed loop to eliminate the driving force for tritium permeation across the upstream heat exchanger, or until the leak rate of tritium from the system through the downstream heat exchanger and bulk fluid leakage equals the input rate to the closed loop (see Section 1.2.4). A balance point will eventually be reached, but the balance point may be above acceptable limits. A purge stream is a controlled leak that removes tritium at a greater rate than the uncontrolled leaks from the closed loop, so that the steady-state concentration of tritium is reduced. Uncontaminated bulk fluid is introduced to the loop at the same rate as the contaminated fluid is purged in order to maintain the total fluid inventory. Complete removal of tritium from a closed loop cannot be achieved by using only a purge stream unless $100 \%$ of the fluid stream is purged and replaced with fresh fluid at all times.

A purge stream may be practical if the tritium accumulation rate is relatively slow in the heat transfer fluid loops, the tipping point for a response to accumulating tritium in the heat transfer fluid streams is relatively high, and the replacement cost of bulk heat transfer fluid is low. Under such circumstances, a purge-and-replace operation may be conducted intermittently, which would likely reduce costs.

\subsubsection{Post-Permeator Evacuation or Flushing}

Capture may be accomplished by evacuation of the space on the downstream side of the permeation membrane or by a flush or sweep of non-contaminated fluid, so that tritium is removed from the vicinity of the membrane surface as it permeates across the permeation window. Either step is performed to reduce the concentration of tritium on the downstream side of the permeation window so that the tritium concentration gradient across the permeation window can be maintained. Unlike a purge stream, no replacement of bulk fluid is needed if the permeation window is permeable to tritium and is not permeable to the bulk fluid.

Evacuation and flushing each have their advantages and disadvantages. Evacuation does not use a diluent, and the tritium captured by the vacuum pump has a much smaller volume than if a 
fluid flush were used. Using a flush gas does not require the use of a vacuum pump, but generates a much larger volume of tritium-contaminated material that will likely require followon treatment to recover separated tritium or to dispose of it as effluent. Evacuation pumps are used to capture tritium in the Savannah River Site Tritium Extraction Facilities [66].

Neither technique works very well when the concentration of tritium is low in the bulk fluid stream. The minimum effective concentration of tritium on the downstream side of the permeator is zero regardless of whether a vacuum or flush is used, and the driving force for permeation across a window becomes exceedingly small at low concentrations. Work at the Savannah River Site showed that reduction in tritium concentration to below $500 \mathrm{ppm}$ is difficult to reach with permeators, and that reduction of tritium from bulk fluid streams using permeators in the single ppm range or less is impractical. By comparison, the concentration of tritium in a gas stream that can be vented to the atmosphere is less than $1 \mathrm{ppt}$ (parts per trillion) or a partial pressure of less than $10^{-7} \mathrm{~Pa}$.

Follow-on treatment systems are needed for the evacuated or flushed tritium in order to properly dispose or recover the tritium removed from the bulk fluid.

\subsubsection{Gettering}

Gettering is the process of adsorbing or absorbing dilute constituents from a gas phase onto or into a solid material by virtue of physical or chemical interactions. The solid material is referred to as a getter. Unlike a permeation material, the binding energy of the constituent/getter interaction is strong enough that the constituent is not released back into the gas phase after capture, and the getter material retains the constituent until such time that the getter material is subject to different physical or chemical conditions (e.g., higher temperature, chemical dissolution, etc.) other than the gettering conditions. Gettering is a dynamic process, and all gettering materials have a storage limit beyond which they cannot capture more material. The rate of capture or surface flux depends upon the concentration of the target constituent in the gas phase, the available surface area, the chemical kinetics of the capture reaction, the amount of constituent already captured by the getter, and other factors. The process of gettering becomes more complicated when there is more than one species in the gas phase that can interact with the getter, and there can be competition among different constituents for getter storage sites.

In the case of hydrogen species, getters are usually metals that can readily dissolve hydrogen and form distinct metal-hydrogen phases such as $\mathrm{Pd}$, or that can form hydrides. Of the two mechanisms, dissolution and hydride formation, hydride formation is a stronger interaction and allows for much greater storage capacity, and therefore hydride formers are used for hydrogen gettering applications. The hydride reaction [68] is shown in Equation 21.

$\mathrm{M}(s)+\frac{\mathrm{x}}{2} \mathrm{H}_{2}(g) \longrightarrow \mathrm{MH}_{\mathrm{x}}(s)$

The gettering reaction is exothermic, and heat is released when hydrogen species are captured by the getter. Consequently, release of hydrogen from a gettering material requires heat input, and higher temperatures above the gettering temperature range are needed to release captured hydrogen. 
Zaluska et al. [69] provides an explanation of the hydride formation process using $\mathrm{Mg}$ as a sample material. Hydrogen becomes adsorbed on the surface of the material where it decomposes into atomic hydrogen. The hydrogen is absorbed by the material and chemically binds with the substrate to make a stable metal hydride compound. The presence of metal oxides or metal hydroxides on the surface of the hydriding material slows down the hydriding process. To increase hydriding rates, hydriding materials may need an "activation" step prior to use that consists of heating the hydriding material to a temperature higher than the intended service range for a certain period of time, which serves to perforate, crack, or decompose oxide and hydroxide surface layers. In the case of magnesium, as described in [67], the activation step consisted of heating magnesium powder over several cycles to above $400^{\circ}$ in the presence of hydrogen and in a vacuum before the magnesium powder could be used as a hydrogen storage medium. In the case of titanium sponge [66], activation consisted of heating the titanium to a range of $500-700^{\circ} \mathrm{C}$ in a vacuum, with faster room-temperature hydriding occurring after heating to $700^{\circ} \mathrm{C}$. The need for an activation process may be eliminated if the surface of the material does not readily form oxides and hydroxides at the temperatures of interest (e.g., Pd, Pt, Ni, Zr), or if the base material is at least partially covered by a thin layer of such material. Pd, Pt, and Ni in particular catalyze the decomposition of molecular hydrogen on the surface, and can be used to enhance hydriding reaction rates [69].

There are a number of metals and metal alloys that can be used as hydrogen getters, and Penzhorn et al. [68] lists a number of metals and compounds along with their operating temperature ranges, hydrogen storage capacities given as a ratio of the number of hydrogen atoms per unit formula, and expected equilibrium hydrogen pressures as a function of temperature expressed as a van't Hoff plot. To operate as a getter, a material must exhibit a very low equilibrium pressure of hydrogen at the hydriding temperature. The equilibrium hydrogen pressure is equivalent to a vapor pressure above a liquid, and is the pressure at which the rate of hydrogen uptake by the getter material equals the rate of hydride dissolution. Figure 13 shows the partial pressure of hydrogen that is in equilibrium with selected metal hydrides or metal alloy hydrides in their pure forms as a function of temperature based on van't Hoff equation data. The metal hydrides are represented as MHx, where $\mathrm{x}$ indicates the ratio of hydrogen to metal in the hydride on a formula basis. The figure shows that hydrides become less stable at increasing temperatures, and that hydride stability is strongly dependent upon the identity of the base metal or alloy. At the temperatures of interest to the NGNP, the metal hydrides based on Ti, Zr, La, Ce, and Y (essentially elements of Group IIIB and IVB) have low hydrogen equilibrium pressures and should be considered for use as high-temperature hydrogen getters. Of those listed, Ti sponge is the least costly material, selling currently at $\$ 4.60-\$ 4.85 / 1 \mathrm{~b}$, while zirconium sponge, the next most expensive, is selling currently for approximately $\$ 140 / \mathrm{lb}$. Unfortunately, $\mathrm{TiH}_{\mathrm{x}}$ has the highest hydrogen equilibrium pressure at a given temperature, and other more expensive hydride formers must be considered when the temperature is above $500^{\circ} \mathrm{C}$ and the concentration of tritium is very low. 


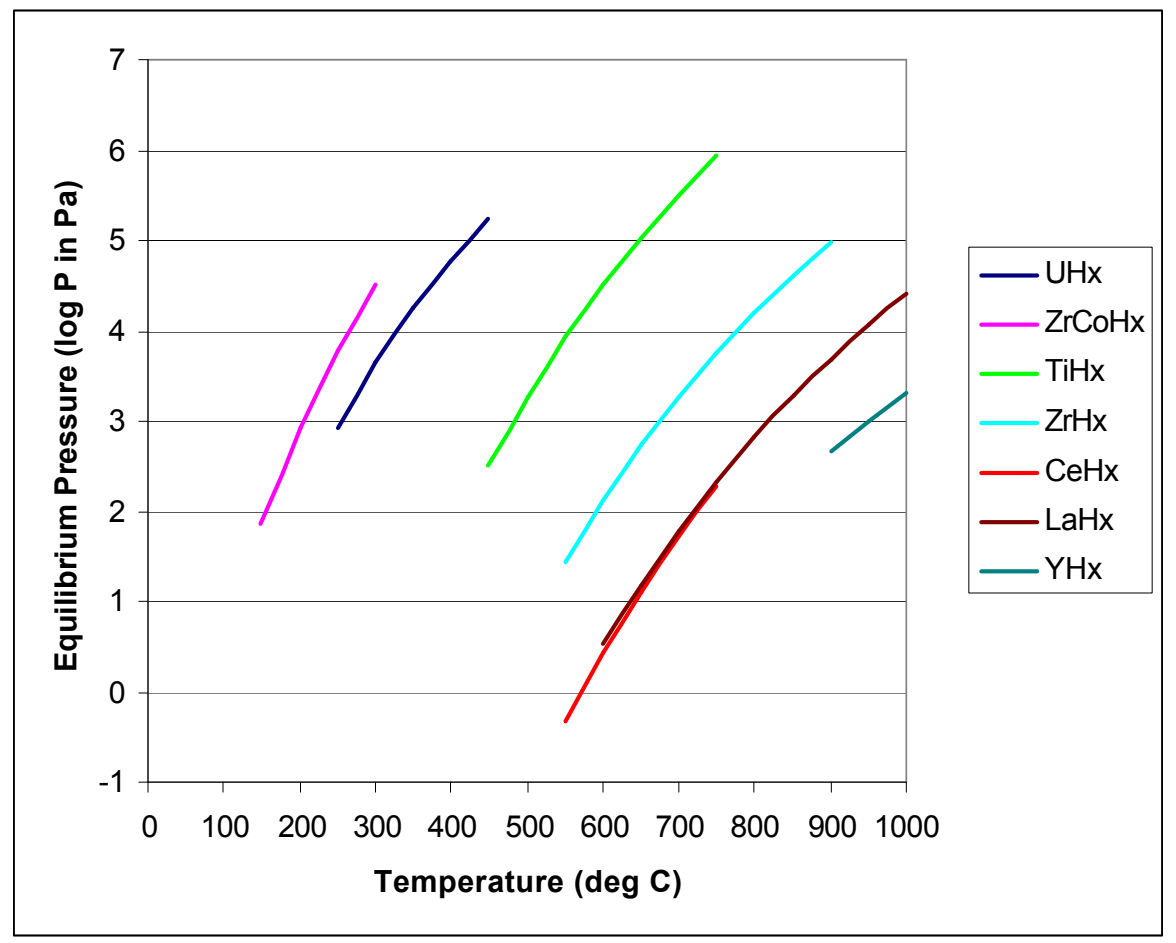

Figure 13. Equilibrium pressure of selected metal or alloy hydrides as a function of temperature based upon van’t Hoff equation [66].

It must be noted that non-saturated metals have lower hydrogen vapor pressures at equilibrium than fully saturated hydrides, and this property can be expressed on a plot of absorption isotherms. Figure 14, which is reproduced from Edwards et al. [70] shows absorption isotherms for $\mathrm{ZrH}_{\mathrm{x}}$, where $\mathrm{x}$ is varied between just about 0.2 to 2.0. Figure 15 shows similar curves that were measured for yttrium by Yannopoulos et al. [71]. The curves have an "S" shape that approaches zero equilibrium pressure at decreasing hydrogen-to-metal atom ratios, have a relatively flat portion, and climb appreciably once the material is saturated with hydrogen. In the case of very dilute hydrogen concentration, as would be experienced in the intermediate heat transfer loops of the NGNP for tritium, getter beds would operate on the far left hand side of the curves and would be able to absorb tritium at very low partial pressures. For example, titanium at $200^{\circ} \mathrm{C}$ can absorb dilute hydrogen, and the resulting titanium hydride is known to have a very low equilibrium pressure of approximately $10^{-14} \mathrm{~Pa}$ [66], which is well below the tritium effluent limit of just under $10^{-7} \mathrm{~Pa}$. 
$\mathrm{H} / \mathrm{Zr}$ atom ratio.

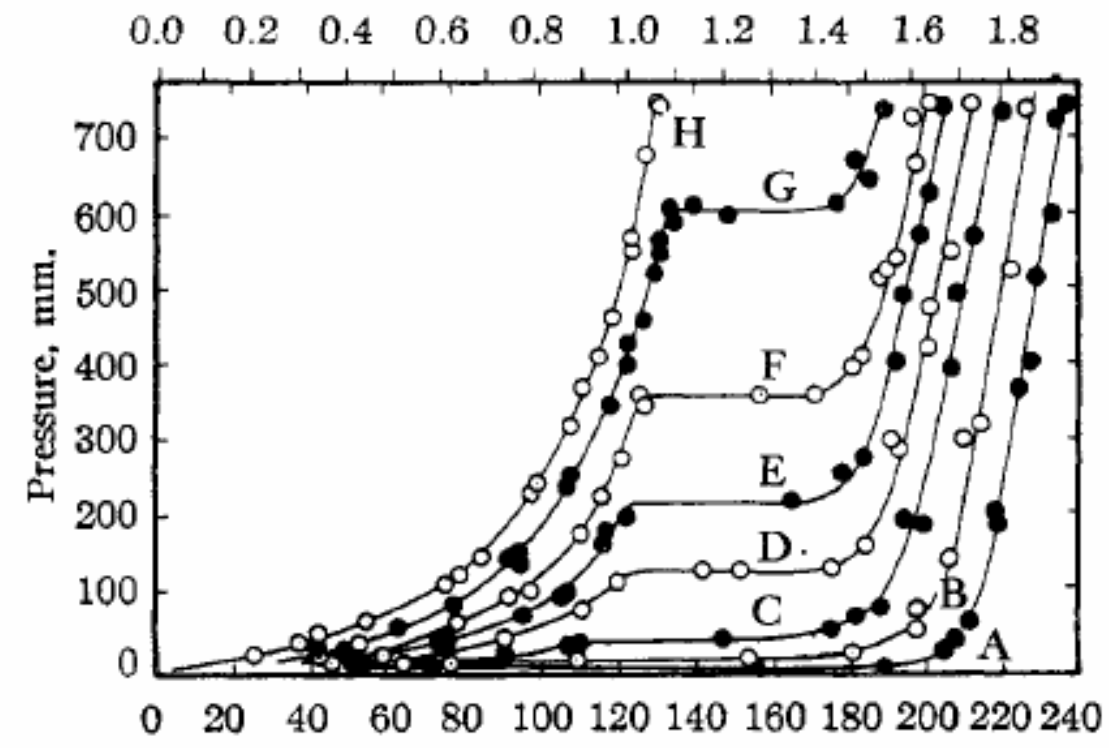

Hydrogen occluded, cc. (N.T.P.)/g. of zirconium.

Figure 14. Isothermal pressure-volume curves for zirconium-hydrogen system at temperatures between $600^{\circ} \mathrm{C}$ and $900^{\circ} \mathrm{C} . \mathrm{A}=600^{\circ} \mathrm{C} ; \mathrm{B}=700 ; \mathrm{C}=750 ; \mathrm{D}=800 ; \mathrm{E}=825 ; \mathrm{F}=850$; $\mathrm{G}=875 ; \mathrm{H}=900^{\circ} \mathrm{C}$. Reproduced from Edwards et al. [70].

is

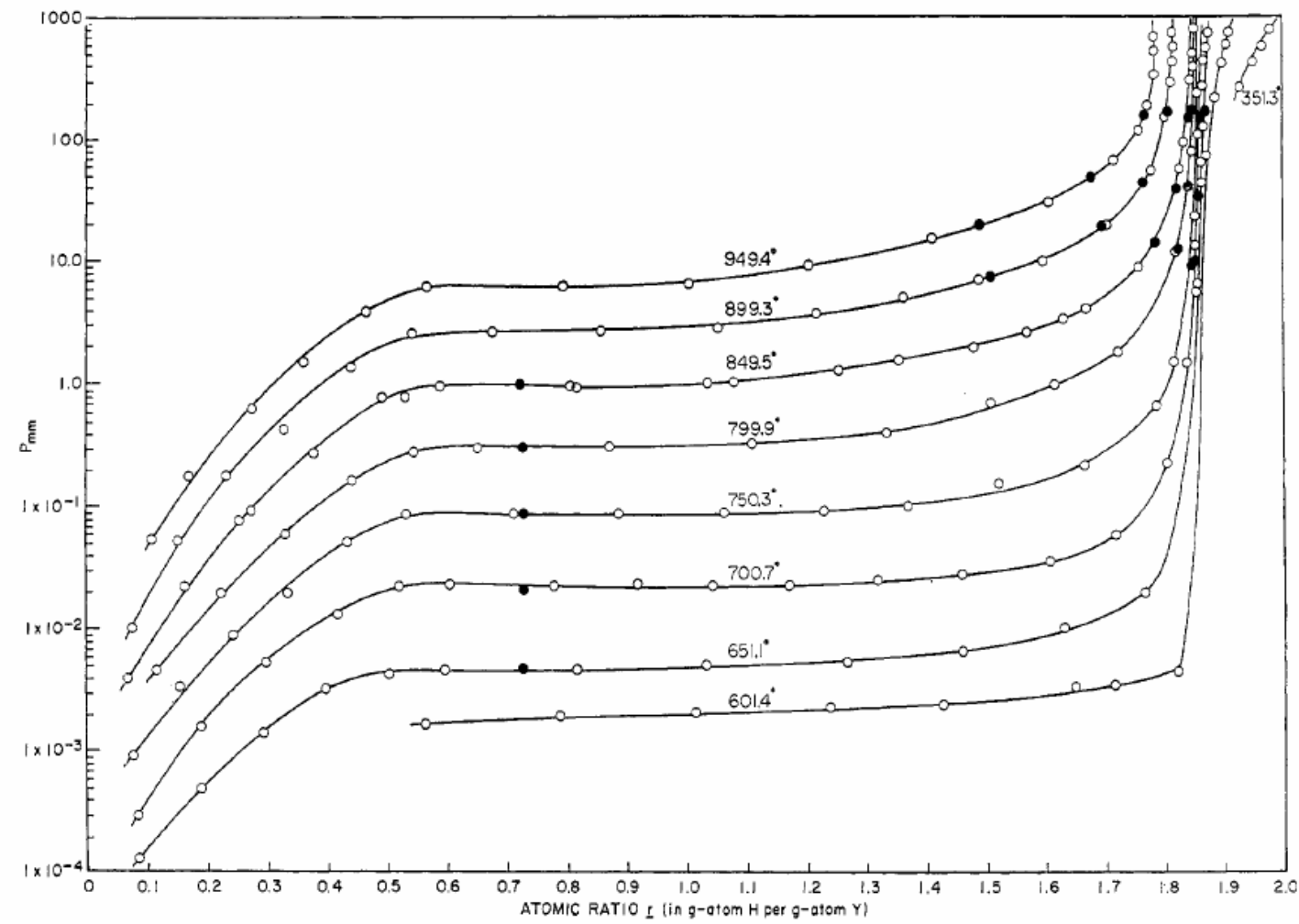

Figure 15. Hydrogen equilibrium pressure curves for yttrium/hydrogen system. Reproduced from Yannopoulos et al. [71]. 
There are some process limitations that must be observed when using strong hydride formers. $\mathrm{Ce}$ and La have melting points of $799^{\circ} \mathrm{C}$ and $921^{\circ} \mathrm{C}$, respectively, which are in the temperature range of the NGNP, and so additional care would need to be taken to not overheat these materials in hydrogen getter applications. These getter materials also form strong oxide compounds which are not easily decomposed, and so act as getters for trace oxygen and water in the gas stream to which they are in contact. Some of these materials also readily form nitrides and carbides when exposed to $\mathrm{N}_{2}$ and carbon compounds. The gettering reactions with hydrogen, oxygen, or nitrogen are all exothermic, and it is possible to overheat or ignite the getter material if the material is swamped with an excess of hydrogen, oxygen, or nitrogen. Finely divided forms of these materials may be pyrophoric in air.

Systems for capturing and storing tritium based on the use of getters have been designed and used at the production scale for nuclear reactors and other nuclear systems that operate at temperatures lower than the NGNP, designs that may be adapted or may inspire updated designs that could be used for higher temperature operations. Savannah River Site first developed and used tritium storage vessels that use $\mathrm{LaNi}_{5-\mathrm{x}} \mathrm{Al}_{\mathrm{x}}$ and $\mathrm{Pd}$ on Kieselguhr (diatomaceous earth) [72], and later developed storage tanks that employ Ti sponge [73] for their tritium facilities. Kherani and Shmayda offer a design for a gas-handling system employing titanium sponge and uranium getters that could be used for the removal and capture of tritium from CANDU reactor gas streams [74]. Paek et al. [75] disclose a tritium storage vessel concept employing Ti sponge that is similar to that proposed in [73], and which is used for tritium removal and storage at the Wolsung Nuclear Generating Station in the Republic of Korea. The Wolsung Station uses CANDU-style reactors that use heavy water as a reactor coolant, and such reactors generate more tritium than their light water counterparts. As a result, CANDU reactor systems require the use of tritium capture and separation systems in order to minimize the loss of tritium to the environment from reactor fluid streams $[76,77]$. Getters may be combined with permeators, where the getter material is essentially the "vacuum pump" that captures tritium that permeates across the permeation window, and such a system was described in U.S. Patent 4,528,003. In this work, planar, tubular, or spherical elements are described that use a hydrogen permeable outer layer of niobium, titanium, palladium, ceramics, or cermet materials having a thickness of less than $10 \mu \mathrm{m}$, and an inner layer or core of hydride forming titanium, zirconium, hafnium, or zirconium aluminum alloy [78]. The permeation material is used to help protect the underlying getter materials from chemical attack by non-hydrogen contaminants in the fluid streams (i.e. $\mathrm{O}_{2}, \mathrm{H}_{2} \mathrm{O}$, $\mathrm{N}_{2}, \mathrm{CO}, \mathrm{CO}_{2}$, etc.).

\subsubsection{Chemical Transformation}

Another method for decreasing the availability of tritium for permeation through heat exchangers or permeation windows is to convert molecular tritium species into tritiated water vapor under conditions where tritiated water is stable and does not decompose. The tritium contained in water vapor permeates less easily through metallic barriers because it first must be reduced to atomic tritium at the metal surface due to surface corrosion mechanisms or catalyzed decomposition of the water vapor, and tritium permeation through the material is reduced as a result.

U.S. Patent 3,937,649 describes a process for removing tritium from high-temperature gascooled reactor streams using oxygen to convert tritiated hydrogen species into tritiated water [79]. A side stream from the main reactor coolant stream is combined with oxygen at elevated temperature, and molecular tritium species in the side stream spontaneously react with the oxygen stream to form tritiated water vapor. Then, the water vapor created is collected in a cold trap, and 
the oxygen and helium coolant streams are then separated using a liquefaction process. The purified helium is heated and re-injected back into the cooling loop, and the separated oxygen stream is recycled to the treatment process, with make-up gases provided as required to maintain steady state conditions in the main reactor cooling loop. The tritiated water collected is collected for disposal.

U.S. Patent 4,178,350 describes a noble metal catalytic process for removing tritium from gaseous streams [80]. A tritium-containing gaseous stream at a temperature of approximately $175^{\circ} \mathrm{C}$ or higher is exposed to a catalyst bed employing $\mathrm{Pt}, \mathrm{Pd}$, or $\mathrm{Rh}$, where the molecular tritium species in the bulk gas stream is converted to tritiated water. The oxygen for the transformation is supplied to the bed in the form of an air or purified oxygen. The tritiated water is then collected on molecular sieve beds that use a zeolite material to trap the water vapor. The patented process is said to be capable of reducing the concentration of tritium in a gaseous stream to below $1 \mathrm{ppb}$.

U.S. Patent 4,673,547 shows a process combining a hydrogen permeation window and a hydrogen oxidation step that is targeted for use in a high-temperature gas-cooled nuclear reactor facility [81]. Permeators are used to separate molecular hydrogen species from the inert gas coolant stream of a high-temperature gas-cooled reactor. On the downstream side of the permeators, hydrogen is carried away from the membrane by an inert gas flush to a down-stream unit, where it is combined with oxygen or an oxidant such as $\mathrm{CuO}$ in order to convert it to tritiated water. From there, the tritiated water is separated from the inert gas stream by condensation or other means.

Direct conversion of tritiated hydrogen to water vapor using an oxide catalyst bed in the main body or side stream of the helium heat transfer streams of the NGNP may be an effective strategy for reducing tritium permeation through heat exchangers, especially if oxide surface layers on the heat exchanger surfaces have already been established. An oxide catalyst bed would be used to convert tritiated hydrogen into HTO (with consequent reduction of the oxide bed) so that tritium is less available to permeate through the heat exchangers than would be molecular tritium species. Schretzmann et al. [82] have identified $\mathrm{CuO}$ as a suitable catalyst for reacting hydrogen in nuclear plants, which is reduced to $\mathrm{Cu}$ at $200^{\circ} \mathrm{C}$ when exposed to hydrogen. Other oxide catalysts might be used for higher temperatures. $\mathrm{MnO}_{2}$ is able to reduce hydrogen effectively in the temperature range $300-500^{\circ} \mathrm{C}$ [83], and $\mathrm{Fe}_{2} \mathrm{O}_{3}$ works effectively as a reduction catalyst over the range 150$880^{\circ} \mathrm{C}[84]$.

If necessary, tritium can be removed from a side stream in the form of tritiated water vapor by capturing it on a getter material. U.S. Patent 4,082,834 describes a Ni-Ti-Zr alloy that is capable of capturing water vapor, oxygen, hydrogen, and other gases between $200-650^{\circ} \mathrm{C}$ [85]. The capture of water vapor in particular occurs by corrosion of the alloy. Water vapor reacts with the alloy to form a metal oxide and a metal hydride with little to no release of hydrogen upon the dissolution of the water vapor.

Additional benefit may be derived by the direct injection of water vapor also, since molecular hydrogen species can undergo isotope exchange reactions with untritiated water to form molecular hydrogen and tritiated water species (see Equation 14 in Section 1.2.3). Some calculations performed by Ohashi and Sherman [86] show this to be the case with an NGNP connected to a high-temperature electrolysis hydrogen production process. Figure 16 shows a graph of water vapor concentration and tritium activity in the hydrogen product as a function of water vapor injection rate. With no water injection, the calculated tritium activity in the hydrogen activity is just above the effluent limit for liquid effluents. With increasing water vapor injection rates, the calculated tritium activity in the hydrogen product can be brought well below effluent 
limits. Figure 17 provides more direct evidence of the effect of water vapor injection on the permeation of tritium through heat exchangers. In the figure, the tritium activity in the tertiary loop coolant of an NGNP is calculated as a function of water vapor injection rate in the secondary cooling loop. According to the calculations, the tritium activity in the tertiary loop might be reduced to below gaseous effluent limits by adding water vapor to the secondary helium loop.

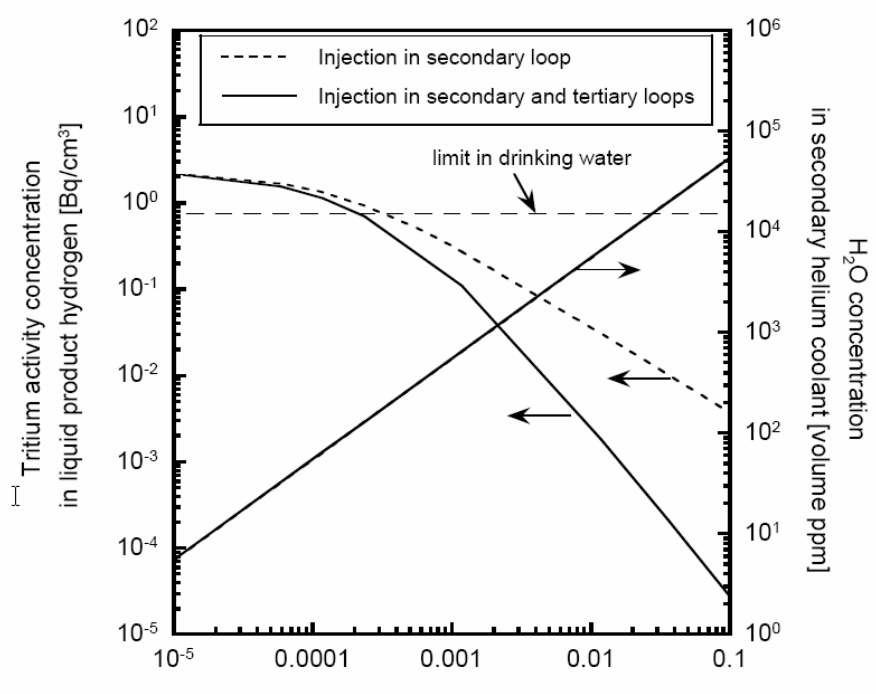

Ratio of $\mathrm{H}_{2} \mathrm{O}$ injection rate to $\mathrm{H}_{2} \mathrm{O}$ feed rate in hydrogen plant [\%]

Figure 16. Calculated tritium activity in the NGNP hydrogen product from an HTE plant as a function of water vapor injection rate in the secondary loop helium coolant.

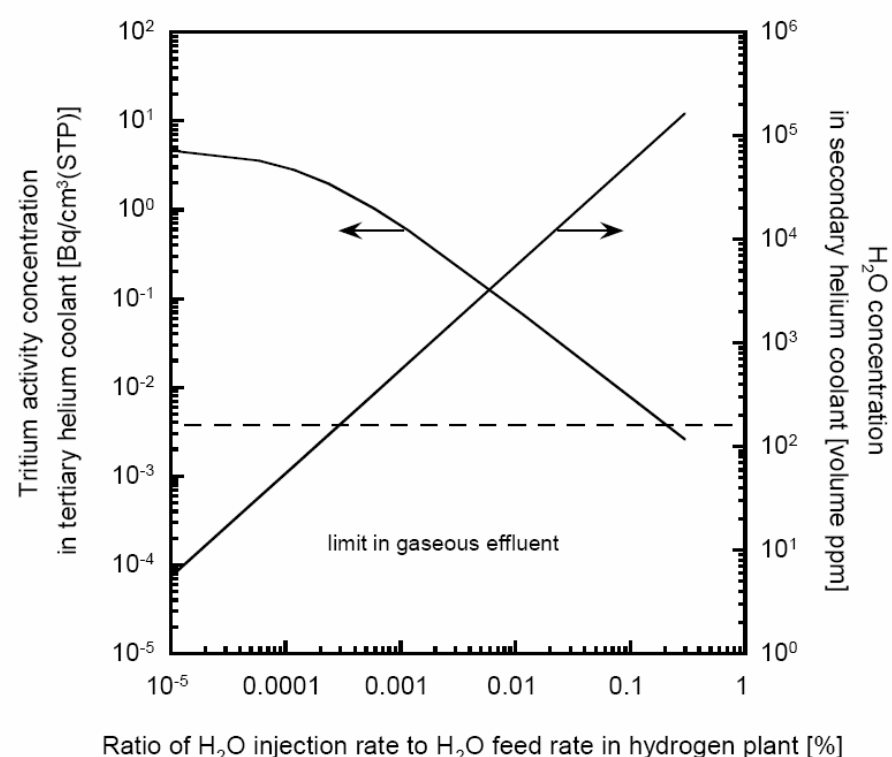

Figure 17. Calculated tritium activity in the NGNP tertiary loop helium coolant hydrogen as a function of water vapor injection rate in the secondary loop helium coolant. 


\subsection{Disposition or Disposal}

Once separated from the nuclear reactor coolant streams, tritium will need to be collected and stored for disposal. Since the amount of tritium that will be generated by the NGNP is small, it is not likely that it will be economic to recover the tritium and use it for other applications. The most compact and stable forms for storing captured tritium will be to store it in the form of a hydride, as described in Section 3.2.3, or as a tritiated water species adsorbed in a zeolite bed, as described in Section 3.2.4. The half-life of tritium is approximately 12.3 years, so inventories of stored tritium will deplete by measurable amounts over the lifetime of the NGNP facility, and so it is likely that all tritium captured during operation of the reactor could be stored until the spent fuel is disposed and the reactor is decommissioned. Tritium generates about $0.3 \mathrm{~W} / \mathrm{g}$ of decay heat, and it is safe to store many grams of tritium in a single location with only a minimal rise in temperature of the storage vessel.

Ultimate disposal pathways may include packaging it with the spent fuel during its disposal process, incorporation of tritium into cement for low-level-waste disposal, and perhaps other means. Commercial nuclear power plants routinely release NRC-authorized gaseous and aqueous streams to the environment that contain tritium at concentrations below the effluent limits [87], and so there may be sites in the U.S. where dilute tritium may be released under the sanction of the NRC.

\subsection{Applications to NGNP}

The concentration of tritium in the heat transfer loops will be driven to low concentrations in order to achieve NRC, EPA, or customer-driven tritium limits in effluents or products, and this will place the tritium concentration at a low enough range that use of permeation windows is impractical. The tritium in the reactor coolant streams must be allowed to interact directly with the capture system without an intervening permeation window in order to minimize any mass transfer resistances to the capture system.

Getter systems involving high-temperature getters may be an effective solution. The data are encouraging that a split-stream system employing $\mathrm{Ti}, \mathrm{Zr}$, or even $\mathrm{Y}$ may be used to remove tritium from helium streams and capture it in the form of a hydride. Once captured, higher temperatures than the capture temperature are needed to release the captured tritium, and the hydrides are expected to be very stable at NGNP temperatures. Alloys of these materials may also be considered if such alloys lead to similar hydride stabilities and faster absorption kinetics.

Conversion of molecular tritium species to tritiated water and injection of water vapor into reactor coolant streams should also be investigated, though the amount of water vapor in a coolant loop may be restricted by corrosion concerns (see Wright [44]). The use of hydrogen oxidation beds and water injection into the heat transfer loops will have to be balanced with the need to maintain proper loop chemistry in order to build and protect oxide-based tritium barriers on the heat exchangers.

If the accumulation time of tritium in the NGNP heat transfer loops is slow compared to the operating schedule of the nuclear reactor, then it may be possible to operate the tritium capture system only intermittently and to alternate its operation with the normal heat transfer loop chemistry control system that will be employed to protect the heat exchanger and structural material surfaces, so that the two systems are not competing to control the loop chemistry. 
Operating scenarios involving intermittent operation will need to be examined to see if this is feasible. 


\section{MITIGATION METHODS}

\subsection{Countercurrent Hydrogen Flow}

The flow of tritium through heat exchanger surfaces may also be reduced by the injection of hydrogen (either intentionally or as a by-product of hydrogen production) downstream of the heat exchanger. Injection of hydrogen downstream of the heat exchanger(s) creates a concentration gradient of hydrogen in the opposite direction of the tritium concentration gradient. This creates a counter-flow of hydrogen within the heat exchanger materials, and this in turn suppresses the downstream flow of tritium.

Kizu and Tanabe [88] describe experiments performed using hydrogen and deuterium to study the effect of providing a co-current and counter-current flow of hydrogen on the flux of deuterium through nickel membranes. According to their experiments, co-current flow of hydrogen with deuterium caused no difference in the flux rate of deuterium through the nickel membrane due to the isotopic exchange reaction of hydrogen with deuterium on the upstream side, which serves to increase the upstream concentration of HD. The counter-current flow of hydrogen reduced the flux of deuterium through the membrane when the ratio of the partial pressure of deuterium to the partial pressure of hydrogen fell below approximately 10, and was reduced significantly when the ratio of partial pressures was less than 1 . Figure 18 is a graph reproduced from [88] that shows a reduction in deuterium flux with an increasing partial pressure ratio of hydrogen to deuterium.

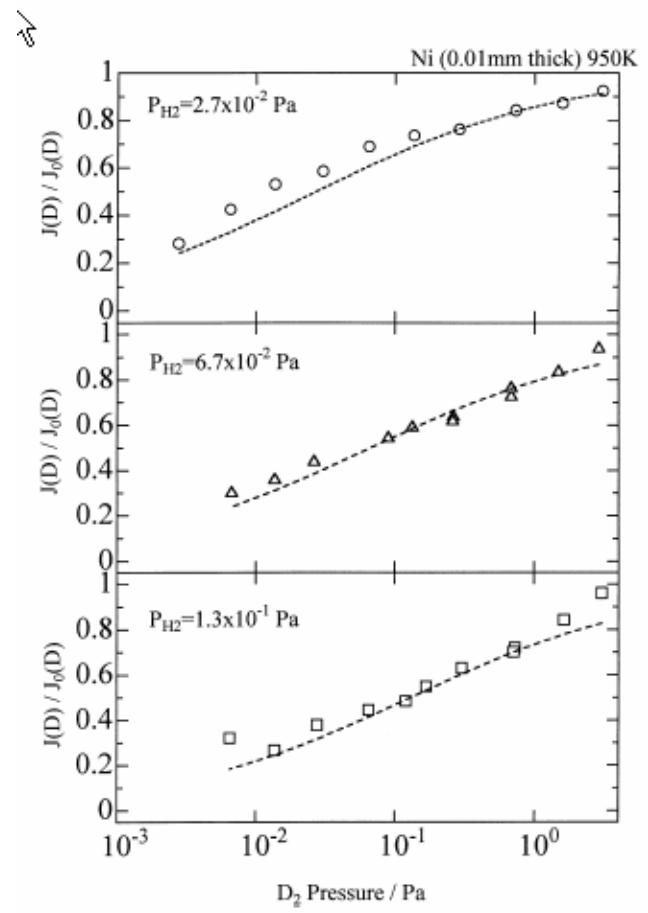

Figure 18. Reduction ratios of deuterium flux in response to hydrogen counter flux through a nickel membrane at several hydrogen partial pressures. 
In the figure, the $y$-axis symbols $\mathrm{J}(\mathrm{D})$ and $\mathrm{J}_{0}(\mathrm{D})$ denote the flux of deuterium with the counterflow of hydrogen $(\mathrm{J}(\mathrm{D}))$ and without the counter flow of hydrogen $\left(\mathrm{J}_{0}(\mathrm{D})\right)$ through the nickel membrane. The symbols denote measured data, and the dashed line denotes modeling results, which were obtained using Equation 22, below.

$$
J(D) / J_{0}(D)=P_{D_{2}}^{0.5} /\left[P_{D_{2}}^{0.5}+\left(S_{H} / S_{D}\right) \times P_{H_{2}}^{0.5}\right]
$$

In Equation 22, $S_{H}$ and $S_{D}$ denote the solubility of hydrogen and deuterium in the membrane material. The mechanism for the suppression of deuterium permeation is believed to be surface blocking of sites by hydrogen, which is dependent upon sub-surface concentrations. The hypothesis that sub-surface concentrations influence the flux of deuterium through the membrane surface is consistent with the 0.5 exponent in Equation 22, which is derived from a Sievert's Law approach to a quantification of the deuterium flux (see Section 1.2.3). Similar results were obtained when Pd membranes were used instead of nickel membranes [89].

The reduction in flux of tritium caused by diffusion of hydrogen was studied in the context of the Peach Bottom HTGR and tritium permeation by Richards et al. [2, 90]. In the study, the tritium flux through steam generators was calculated based upon the measured concentrations of hydrogen and tritium in the primary coolant, and the observed downstream permeation of tritium through the steam generator tube walls, which were composed of Alloy $800 \mathrm{H}$. An equation was developed that described the flux of tritium through the steam generator walls which is shown as Equation 23.

$$
\text { flux }=5.326 \times 10^{-11} \frac{P_{T}}{\sqrt{P_{H_{2}}}} \frac{\exp \left(-5.194 \times 10^{4} / \mathrm{RT}\right)}{t_{m}}\left[\mathrm{~m}^{3}(\mathrm{STP}) / \mathrm{m} \bullet \mathrm{s} \bullet \mathrm{Pa}^{0.5}\right]
$$

In Equation 23, $P$ is the partial pressure of tritium or hydrogen, $t_{m}$ is the thickness of the steam generator tube wall, $\mathrm{R}$ is the ideal gas constant, and $\mathrm{T}$ is the temperature in Kelvin. The study did not distinguish between co-current and countercurrent flow of hydrogen, and no data are presented on the concentration of hydrogen in the steam generator tubes. Given the results of Kizu and Tanabe $[84,85]$, however, it is likely that counter flow of hydrogen was the cause of the reduction in tritium permeation rate across the steam generator tubes rather than just the mere presence of hydrogen with tritium.

The upstream diffusion of hydrogen will occur when there is a hydrogen gradient, and a hydrogen gradient must be created in order to cause counter-flow. At the start of injection, a gradient will exist because there will be very little hydrogen upstream, but hydrogen concentrations across the system equilibrate eventually if there is no hydrogen removal mechanism upstream of the heat exchanger, and the counter diffusion condition will dissipate. A hydrogen removal system is needed upstream from the heat exchanger surfaces to maintain a steady-state hydrogen concentration gradient, and the tritium removal system(s) serve this purpose. The rate of hydrogen injection will need to be balanced with the capacity of the tritium removal systems in order to avoid swamping it with hydrogen. Also, the heat transfer loop chemistry conditions must be adjusted to accommodate a larger hydrogen flux. 


\subsection{Applications to NGNP}

Counter-flow of hydrogen is an option that may be considered for use in the NGNP as an additional tritium control measure for metallic heat exchangers. In the case of high-temperature electrolysis, metallic heat exchangers are being considered for the steam generator tubes, and hydrogen produced in the electrolytic cells will diffuse upstream in an uncontrolled fashion, and the permeation of tritium into the hydrogen process will be reduced without deliberate hydrogen injection. For the S-I process and the Hybrid Sulfur process, the hydrogen production steps take place in production units other than the high-temperature sections of the processes, and no hydrogen will be available automatically from the hydrogen generation process to create a counter flow condition, and additional hydrogen would need to be injected upstream from the hydrogen plant. If hydrogen is present in the heat transfer loops, either due to accidental or deliberate counter-flow of hydrogen, then the tritium capture systems must be sized to retain both tritium and hydrogen, since the capture systems discussed here generally do not distinguish between hydrogen isotopes. Heat transfer loop chemistry controls will need to be adjusted to account for excess hydrogen, so that in-situ tritium barrier coatings and corrosion controls can be maintained. 
49 of 60 


\section{RESEARCH AND DEVELOPMENT NEEDS FOR NGNP}

Additional experimental and modeling work will be needed to adapt suggested technologies in the literature to the needs of the NGNP Project. A general list of research and development needs in the NGNP tritium area is provided in Table 5. In the table, research areas are ordered. Areas of highest importance during FY09 are placed in Sequence 1. Areas that may need to be pursued as back-up or alternative technologies to those placed in Sequence 1, or which may not be needed until after Sequence 1 activities have been completed, are placed in Sequence 2. Areas placed in Sequence 3 are to be executed after Sequence 1 and/or Sequence 2 activities have been completed. It is assumed that experiments performed in Sequence 1 and Sequence 2 may be completed using hydrogen and/or deuterium, while Sequence 3 experiments will require the use of tritium to qualify a particular tritium technology for service in the NGNP.

Table 5. Recommendations for R\&D of Tritium Barriers/Separation Systems for the NGNP

\begin{tabular}{|c|c|c|}
\hline Sequence & Topic & Suggested Work \\
\hline \multicolumn{3}{|c|}{ Tritium Barriers } \\
\hline 1 & $\begin{array}{l}\text { Experimental: In-situ } \\
\text { oxide tritium barriers }\end{array}$ & $\begin{array}{l}\text { - Permeability versus temperature and } \mathrm{H}, \mathrm{D}, \mathrm{T} \\
\text { partial pressure } \\
\text { - } \quad \text { Determine oxide layer preparation recipe for } \\
\text { Inconel } 617 / \text { Haynes } 230 \\
\text { - } \quad \text { Measure permeability response after temperature } \\
\text { transients } \\
\text { - } \quad \begin{array}{l}\text { Determine method(s) of healing damaged barriers } \\
\text { and study healing rates }\end{array} \\
\text { - Study effect of adding barrier layer on just one } \\
\text { side of the base material or both sides of the base } \\
\text { material }\end{array}$ \\
\hline 2 & $\begin{array}{l}\text { Experimental: } \\
\text { Aluminide-based tritium } \\
\text { barriers }\end{array}$ & 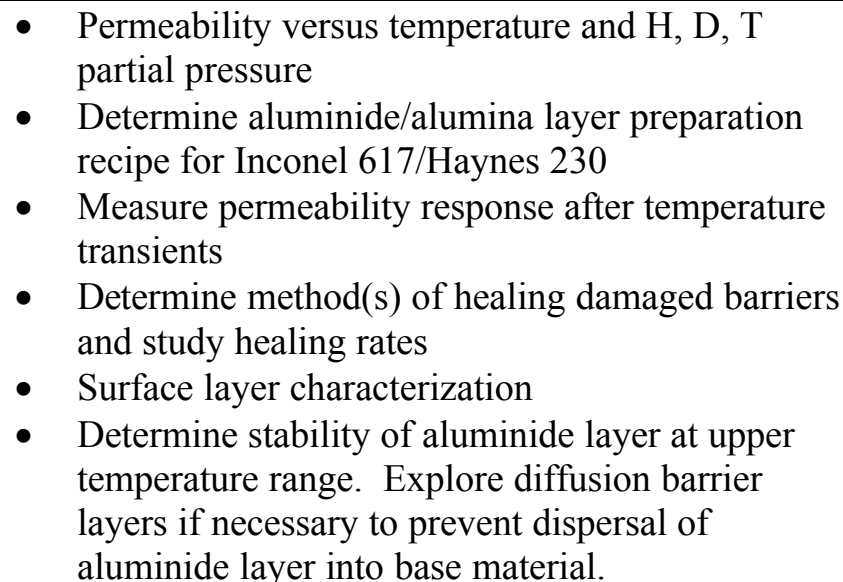 \\
\hline
\end{tabular}




\begin{tabular}{|c|c|c|}
\hline Sequence & Topic & Suggested Work \\
\hline \multicolumn{3}{|c|}{ Tritium Capture Systems } \\
\hline 1 & $\begin{array}{l}\text { Experimental: } \mathrm{Ti}, \mathrm{Zr}, \mathrm{Y} \\
\text { as high-temp tritium } \\
\text { getters (other getter } \\
\text { materials are possible) }\end{array}$ & $\begin{array}{l}\text { - Absorption kinetics } \\
\text { - Getter capacity as function of temperature (bed } \\
\text { breakthrough, storage capacity, etc.) } \\
\text { - Effects of changing getter morphology (sponge, } \\
\text { foil, etc.) } \\
\text { - Effects of contaminant spikes on performance } \\
\text { (excess water vapor, oxygen) } \\
\text { - Saturated getter stability for storage purposes }\end{array}$ \\
\hline 1 & $\begin{array}{l}\text { Experimental: Ti, } \mathrm{Zr}, \mathrm{Y} \text {, } \\
\text { Ni-Ti-Zr as high-temp } \\
\text { moisture getters (other } \\
\text { materials are possible) }\end{array}$ & $\begin{array}{l}\text { - Absorption kinetics } \\
\text { - Getter capacity as function of temperature (bed } \\
\text { breakthrough, storage capacity, etc.) } \\
\text { - Effects of changing getter morphology (sponge, } \\
\text { foil, etc.) } \\
\text { - Effect of excess oxygen on performance }\end{array}$ \\
\hline 2 & $\begin{array}{l}\text { Experimental: } \mathrm{CuO} \text {, } \\
\mathrm{MgO}, \mathrm{Fe}_{2} \mathrm{O}_{3} \text { as hydrogen } \\
\text { oxidizers }\end{array}$ & $\begin{array}{ll}\text { - } & \text { Reaction kinetics } \\
\text { - } & \text { Reaction conversion versus temperature, water } \\
\text { vapor concentration } \\
\text { - Bed stability } \\
\text { - Effects of oxygen, water vapor on conversion } \\
\text { reaction }\end{array}$ \\
\hline \multicolumn{3}{|c|}{ Integrated Tritium Contamination Prevention Systems } \\
\hline 1 & $\begin{array}{l}\text { Modeling: Dynamic } \\
\text { modeling of tritium } \\
\text { migration in NGNP }\end{array}$ & $\begin{array}{l}\text { - Validate THYTAN code or other code/software } \\
\text { for use with NGNP tritium migration work } \\
\text { Analyze NGNP tritium migration scenarios using } \\
\text { updated NGNP configurations and physical data } \\
\text { from the experiments when it becomes available. }\end{array}$ \\
\hline 2 & $\begin{array}{l}\text { Design: Conceptual } \\
\text { Design of NGNP Tritium } \\
\text { Barrier and Getter System }\end{array}$ & $\begin{array}{l}\text { - Develop conceptual design of tritium barrier and } \\
\text { capture system for NGNP System Interface } \\
\text { - Mass/energy balances } \\
\text { - Equipment sizing } \\
\text { - Operating schedules } \\
\text { - Capital and operating costs } \\
\text { - Disposal path for waste materials } \\
\end{array}$ \\
\hline 3 & $\begin{array}{l}\text { Integrated system testing } \\
\text { using tritium instead of } \\
\text { hydrogen or deuterium }\end{array}$ & $\begin{array}{l}\text { - Intended to provide experimental testing and } \\
\text { qualification of methods/equipment at higher } \\
\text { Technology Readiness Levels (TRLs) } \\
\text { - Goal is to reach TRL sufficient to install in NGNP } \\
\text { facility }\end{array}$ \\
\hline \multicolumn{3}{|c|}{ Instrumentation } \\
\hline 1 & $\begin{array}{l}\text { Literature Survey and } \\
\text { Experimental: Tritium } \\
\text { detection instrumentation }\end{array}$ & $\begin{array}{l}\text { Examine available instrumentation for } \\
\text { quantification of very dilute tritium } \\
\text { - Adopt/adapt/develop concept(s) for on-line } \\
\text { measurements } \\
\text { - Test proposed on-line tritium detection } \\
\text { instrumentation }\end{array}$ \\
\hline
\end{tabular}


52 of 60 
53 of 60 


\section{REFERENCES}

[1] NGNP Project, Next Generation Nuclear Plant Project: Preliminary Project Plan, PLN2489, Idaho National Laboratory, June 2007.

[2] H. Ohashi, S.R. Sherman, Tritium Movement and Accumulation in the NGNP System Interface and Hydrogen Plant, INL/EXT-07-12746, Idaho National Laboratory, June 2007.

[3] D. Greneche, W.J. Szymczak, "The AREVA HTR Fuel Cycle: An analysis of technical issues and potential industrial solutions," Nucl. Eng. and Des., Vol 236, 2006, pp. 635-642.

[4] U.S. DOE, A Technology Roadmap for Generation-IV Nuclear Energy Systems, GIF-00200, U.S. DOE Nuclear Energy Research Advisory Committee and the Generation IV International Forum, December 2002.

[5] U.S. DOE, The U.S. Generation-IV Implementation Strategy, DOE Office of Nuclear Energy, September 2003.

[6] 42 USC 14801, 2005, "Energy Policy Act of 2005," (EPACT 2005), Federal Energy Regulatory Commission, August 8, 2005.

[7] U.S. DOE, DOE Handbook: Tritium Handling and Safe Storage, DOE-HNBK-1129-99, Mar 1999.

[8] E.L. Albenesius, "Tritium as a Product of Fission," Physical Review Letters, Vol 3, No 6, pp 274-275, Sep 15, 1959.

[9] C. Wagemans, P. D'Hondt, P. Schillebeeckx, "Triton and alpha emission in the thermalneutron-induced ternary fission of ${ }^{233} \mathrm{U},{ }_{235} \mathrm{U},{ }^{239} \mathrm{Pu}$ and ${ }^{241} \mathrm{Pu}$," Physical Review C, Vol 33, No 3, pp 943-953, Mar 1986.

[10] J.E. Till, Savannah River Site News: Dose Reconstruction, Phase II: Source Term Calculation and Environmental Pathway Data Retrieval, Vol II, No 3, July 1997.

[11] L. Jowa, "Public Health Goal for Tritium in Drinking Water," California Environmental Protection Agency, March 2006.

[12] K. Verfondern, T. Nishihara, "The Particular Safety Aspects of the Combined HTTR/Steam Reforming Complex for Nuclear Hydrogen Production," $1{ }^{\text {st }}$ COE-INES Int. Symposium, INES-1, Oct 31-Nov 4, 2004, Tokyo, Japan.

[13] Canadian Nuclear Safety Commission, http://www.nuclearsafety.gc.ca/eng/newsroom/issues/tritium/tritium.cfm\#table 2

[14] J.R. Welty, C.E. Wicks, R.E. Wilson, Fundamentals of Momentum, Heat, and Mass Transfer, $3^{\text {rd }}$ Edition, John Wiley \& Sons, New York, 1984.

[15] K. Malek, M.-O. Coppens, "Knudsen self- and Fickian diffusion in rough nanoporous media," J. Chem. Phys, Vol 119, No 5, Aug 1, 2003, pp 2801-2811. 
[16] B.L. Bischoff, R.D. Judkins, T.R. Armstrong, "Microporous Inorganic Membranes for Hydrogen Purification," Oak Ridge National Laboratory, DOE Workshop on Hydrogen Separations and Purification Technologies, Arlington, Virginia, September 8, 2004.

[17] A. Kheshavaraja, N.E. Jacob, A.V. Ramaswamy, "Thermal decomposition of coprecipitated oxide hydrates of zirconium and manganese," Thermochemical Acta, Vol 254, 1995, pp. 267-275.

[18] U.S. Patent 5,259,870, "Hydrogen Permeable Composite Metal Membrane,” D.J. Englund, Bend Research, Inc., Nov. 9, 1993.

[19] M.A. Fütterer, X. Raepsaet, E. Proust, "Tritium permeation through helium-heated steam generators of ceramic breeder blankets of DEMO," Fus. Eng. \& Des., Vol 29, 1995, pp 225-232.

[20] N. Sakaba, H. Ohashi, T. Takeda, "Hydrogen permeation through heat transfer pipes made of Hastelloy XR during the initial $950^{\circ} \mathrm{C}$ operation of the HTTR," J. of Nucl. Mat., Vol 353, 2006, pp 42-51.

[21] M. Glugla, I.R. Crestescu, I. Crestescu, D. Demange, "Hydrogen isotope separation by permeation through palladium membranes," J. Nucl. Mat., Vol 355, 2006, pp 47-53.

[22] R.A. Oriani, "The Physical and Metallurgical Aspects of Hydrogen in Metals," ICCF4, Fourth International Conference on Cold Fusion, 1993, Lahaina, Maui, Hawaii

[23] R.H. Jones, G.J. Thomas, Materials for a Hydrogen Economy, CRC Press, Boca Raton, Florida, 2008.

[24] Galluci, F., De Falco, M., Tosti, S., Marrelli, L., Basile, A., "The effect of hydrogen flux pressure and temperature dependence on the membrane reactor performances," Int. J. of Hydrogen Energy, Vol 32, 2007, 4052-4058.

[25] S.R. Sherman, Y. Chen, HX Testing Requirements and Facility Needs for the NHI/NGNP Project, WSRC-STI-2008-00152, Savannah River National Laboratory, March 2008.

[26] C.W. Extrand, D. Ware, J. Kirchgessner, J. Schlueter, "Quantifying Leak Rates in Gas Handling Systems," Ind. Chem. Eng. Res., Vol 47, 2008, pp 1304-1309.

[27] H. Ohashi, N. Sakaba, T. Nishihara, Y. Inagaki, K. Kunitomi, "Numerical Study on Tritium Behavior by Using Isotope Exchange Reactions in Thermochemical Water-Splitting IodineSulfur Process," J. Nucl. Sci. and Tech., Vol 44, No 11, 2007, pp 1407-1420.

[28] H. Nakamura, M. Nishi, "Experimental Evaluation of tritium permeation through stainless steel tubes of heat exchanger from primary water to secondary water in ITER," J. of Nucl. Mater., Vols 329-333, 2004, pp 183-187.

[29] K.R. Schultz, L.C. Brown, G.E. Besenbruch, C.J. Hamilton, "Large Scale Production of Hydrogen Using Nuclear Energy for the Hydrogen Economy," GA-A24265, Proceedings of the National Hydrogen Association 14 ${ }^{\text {th }}$ Annual Conference, April 6-9, 2003. 
[30] W.A. Summers, M.B. Gorensek, M.R. Buckner, "The Hybrid Sulfur Cycle for Nuclear Hydrogen Production,” Proceedings of Global 2005, Paper 097, Tsukuba, Japan, October 9-13, 2005.

[31] J.S. Herring, J.E. O’Brien, C.M. Stoots, G.L. Hawkes, J.J. Hartvigsen, M. Shahnam, "Progress in high-temperature electrolysis for hydrogen production using SOFC technology," Int. J. of Hy. Energy, Vol 32, 2007, pp 440-450.

[32] M.A. Fütterer, X. Raepsaet, E. Proust, "Tritium permeation through helium-heated steam generators of ceramic breeder blankets for DEMO," Fusion Eng. and Des., Vol 29, 1995, pp 225-232.

[33] B.G. Hong, D.W. Lee, S.J. Wang, Y. Kim, W.K. In, K.H. Yoon, "Basic concepts of DEMO and a design of a helium-cooled molten lithium blanket for a testing in ITER," Fusion Eng. and Design, Vol 82, 2007, pp 2399-2405.

[34] K.S. Forcey, D.K. Ross, C.H. Wu, "The formation of hydrogen permeation barriers on steels by aluminising," J. of Nucl. Mater., Vol 182, 1991, pp 36-51.

[35] E.R. Gilbert, R.P. Allen, D.L. Baldwin, R.D. Bell, J.L. Brimhall, R.G. Clemmer, S.C. Marschman, M.A. McKinnon, R.E. Page, H.G. Powers, S.G. Chalk, "Tritium Permeation and Related Studies on Barrier Treated 316 Stainless Steel," Fusion Technology, Vol 21, March 1992, pp 739-744.

[36] G.W. Hollenberg, E.P. Simonen, G. Kalinen, A. Terlain, “Tritium/Hydrogen Barrier Development," PNL-SA-24235, Pacific Northwest National Laboratory, Third International Symposium on Nuclear Fusion Technology, June 27-July 1, 1994, Los Angeles, California.

[37] P.S. Korinko, J.H. Scogin, E. Clark, "Process Development of Aluminide Coatings for Hydrogen Isotope Permeation Resistance," WSRC-MS-2001-00266, Washington Savannah River Company, Proceedings of the $6^{\text {th }}$ International Conference on Tritium Science and Technology (TRITIUM 2001), Tsukuba, Japan, Nov. 11-16, 2001.

[38] P.S. Korinko, N. Thakur, "Permeation Barrier Coatings for the Helical Heat Exchanger," WSRC-TR-98-00429, Washington Savannah River Company, 1998.

[39] U.S. Patent 5,366,765, “Aqueous Slurry Coating System for Aluminide Coatings," M.S. Maliniak, D.J. Orzel, F.P. Laram, D.E. DeSaulniers, United Technologies Corporation, November 22, 1994.

[40] U.S. Patent 6,444,054, "Slurry Compositions for Diffusion Coatings," T. Kircher, B.G. McMordie, S. Shankar, Sermatech International, Inc., September 2, 2002.

[41] M. Nakamichi, H. Kawamura, T. Teratani, "Characterization of Chemical Densified Coatings as Tritium Permeation Barrier," J. Nucl. Sci. and Tech., Vol 38, No 11, November 2001, pp 1007-1013.

[42] Z. Yao, J. Hao, C. Zhou, C. Shan, J. Yu, "The permeation of tritium through 316L stainless steel with multiple coatings,” J. of Nucl. Mater., Vols 283-287, 2000, pp 1287-1291. 
[43] H.P. Buchkremer, R. Hecker, H. Jonas, H.J. Leyers, D. Stöver, “Oxide Films on Austenitic HTR Heat Exchanger Materials as a Tritium Permeation Barrier," IAEA Specialist Meeting on Heat Exchanging Components of Gas-Cooled Reactors, Düsseldorf, April 16-19, 1984.

[44] R.N. Wright, Kinetics of Gas Reactions and Environmental Degradation in NGNP Helium, INL/EXT-06-11494, Idaho National Laboratory, June 2006.

[45] P.S. Korinko, "High Temperature Environmental Interactions of Inconel 617: A Paper Study for the TEF," WSRC-TR-2000-00136, Washington Savannah River Company, May 2000 .

[46] U.S. Patent 1,174,631, “Apparatus for Separating Gases,” W.O. Snelling, March 7, 1916.

[47] N.M. Peachy, R.C. Snow, R.C. Dye, "Composite Pd/Ta metal membranes for hydrogen separation,” J. of Membrane Sci., Vol 111, 1996, pp 123-133.

[48] U.S. Patent 2,773,561, "Silver-Palladium Film for Separation and Purification of Hydrogen," J.B. Hunter, The Atlantic Refining Company, December 11, 1956.

[49] U.S. Patent 3,155,467, "Palladium Alloy Permeable Wall for the Separation and Purification of Hydrogen," Y. Yamamoto, R. Goto, Nippon Juinsuiso Kabushiki Kaisha, November 3, 1964.

[50] U.S. Patent 5,215,729, “Composite Metal Membrane for Hydrogen Extraction,” R.E. Buxbaum, June 1, 1993.

[51] U.S. Patent 5,149,420, "Method for Plating Palladium," R.E. Buxbaum, Michigan State University, September 22, 1992.

[52] U.S. Patent 6,569,226, "Metal/Ceramic Composites with High Hydrogen Permeability," S.E. Dorris, T.H. Lee, U. Balachandran, United States Department of Energy, May 27, 2003.

[53] S. Hopkins, "High-Performance, Durable, Palladium-Alloy Membrane for Hydrogen Separation and Purification," Project PDP\#11, Pall Corporation, 2007 DOE H2 Merit Review, Arlington, VA, May 15, 2007.

[54] Y.H. Ma, B.C. Akis, M.E. Ayturk, F. Guazzone, E.E. Engwall, I.P. Mardilovich, "Characterization of Intermetallic Diffusion Barrier and Alloy Formation of $\mathrm{Pd} / \mathrm{Cu}$ and Pd/Ag Porous Stainless Steel Composite Membranes," Ind. Eng. Chem. Res., Vol 43, 2004, pp 2936-2945.

[55] ITER Technical Basis, Section 3.1: Tritium Plant and Detritiation, G A0 FDR 1 01-07-13 R1.0.

[56] B. Bornschein, M. Glugla, K. Günther, R. Lässer, T.L. Le, K.H. Simon, S. Welte, "Tritium tests with a technical PERMCAT for final clean-up of ITER exhaust," Fus. Eng. and Design, Vol 69, 2003, pp 51-56.

[57] See www.iter.org/a/n1/dowloads/construction schedule.pdf. 
[58] C. Nishimura, M. Komaki, S. Hwang, M. Amano, "V-Ni alloy membranes for hydrogen purification," J. of Alloys and Compounds, Vols 330-332, 2002, pp 902-906.

[59] M.R. Louthan Jr., R.G. Derrick, "Permeability of nickel to high pressure hydrogen isotopes," Scripta Metallurgica, Vol 10, Issue 1, January 1976, pp 53-55.

[60] J. Xu, X.K. Sun, W.X. Chen, Y.Y. Li, "Hydrogen Permeation and Diffusion in Iron-Based Superalloys," Acta Metallurg. Mater., Vol 41, No. 5, 1993, pp 1455-1459.

[61] A. Prabhu, S.T. Oyama, "Highly hydrogen selective ceramic membranes: application to the transformation of greenhouse gases," J. of Membrane Sci., Vol 176, 2000, pp 233-248.

[62] H. Iwahara, Y. Asakura, K. Katahira, M. Tanaka, "Prospect of hydrogen technology using proton-conducting membranes," Solid State Ionics, Vol 168, 2004, pp 299-310.

[63] K. Hou, R. Hughes, "The effect of external mass transfer, competitive adsorption and coking on hydrogen permeation through Pd/Ag membranes," J. of Membrane Science, Vol 206, 2002, pp 119-130.

[64] S.H. Jung, K. Kusakabe, S. Morooka, S.D. Kim, "Effects of coexisting hydrocarbons on hydrogen permeation through a palladium membrane," J. of Membrane Science, Vol 170, 2000, pp 53-60.

[65] U.S. Patent 5,498,278, “Composite Hydrogen Separation Element and Module,” D.J. Endlund, Bend Research Inc., March 12, 1996.

[66] E.A. Clark, D.A. Dauchess, L.K. Heung, R.L. Rabun, T. Motyka, "Experience with Palladium Diffusers in Tritium Processing," Fusion Technology, Vol 28, October 1995, pp 566-572.

[67] J.E. Klein, "Shell Temperatures for a Single Heater Diffuser," Fusion Science and Technology, Vol 48, No 1, July/August 2005, pp. 59-62.

[68] R.-D. Penzhorn, M. Devillers, M. Sirch, "Evaluation of ZrCo and Other Getters for Tritium Handling and Storage," J. of Nucl. Mater., Vol 170, 1990, pp 217-231.

[69] A. Zaluska, L. Zaluska, J.O. Ström-Olsen, "Nanocrystalline magnesium for hydrogen storage," J. of Alloys and Compounds, Vol 288, 1999, pp 217-225.

[70] R.K. Edwards, P. Levesque, D. Cubicciotti, "Solid Solution Equilibria in the ZirconiumHydrogen System," J. of the Am. Chem. Soc., Vol 77, No 5, March 5, 1955, pp 1307-1311.

[71] L.N. Yannopoulos, R.K. Edwards, P.G. Wahlbeck, "The Thermodynamics of the YttriumHydrogen System," Journal of Physical Chemistry, Vol 69, No 8, August 1965, pp 25102515.

[72] M.S. Ortman, T.J. Warren, D.J. Smith, "Use of Metal Hydrides for Handling Tritium," Fusion Technology, Vol 8, 1985, pp 2330-2336.

[73] J.E. Klein, “A 1600-Liter Tritium Hydride Storage Vessel,” WSRC-MS-2001-00247, Westinghouse Savannah River Company, 2001. 
[74] N.P. Kherani, W.T. Shmayda, "Gas Handling System Using Titanium-Sponge and Uranium Bulk Getters,” Fusion Technology, Vol 8, 1985, pp 2399-2406.

[75] S. Paek, D. Ahn, K. Kim, S. Yim, M. Lee, H. Chung, "Performance Test of the Tritium Storage Vessel," Korean Chemical Engineering Research, Vol 42, No 6, December 2004, pp 771-775.

[76] C.K. Kim, M.J. Han, "Dose assessment and behavior of tritium in environmental samples around Wolsung nuclear power plant," Applied Radiation and Isotopes, Vol 50, 1999, pp 783-791.

[77] Taekun P., Seonki K., "Tritium: its generation and pathways to the environment at CANDU 6 generating stations," Nuclear Engineering and Design, Vol 163, No 3, July 1996, pp 405411.

[78] U.S. Patent 4,528,003, “Apparatus for Separating Gaseous Hydrogen Isotopes,” H. Dittrich, H. Frey, Kernforschungszentrum Karlsruhe GmbH, July 9, 1985.

[79] U.S. Patent 3,937,649, "Process and System for Removing Tritium,” J.N. Ridgely, February 10, 1976.

[80] U.S. Patent 4,178,350, "Removal of Tritium and Tritium-Containing Compounds From a Gaseous Stream,” M.F. Collins, R. Michelak, Englehard Minerals and Chemicals, December 11, 1979.

[81] U.S. Patent 4,673,547, "Process for Separation of Hydrogen and/or Deuterium and Tritium from an Inert Gas Flow and Apparatus for Effectuation of Process in the Cooling Gas Circuit of a Gas-Cooled Nuclear Reactor," N. Iniotakis, C.-B von der Decken, R. Hecker, R. Schulten, Kernforschungsanlage Julich Gesellschaft mit Beschrankter Haftung, June 16, 1987.

[82] U.S. Patent 4,407,774, "Method for Preventing Dangerous Hydrogen Accumulation in Nuclear Reactor Containments," K. Schretzmann, K., S. Dorner, G. Schumacher, Kernforschungszentrum Karlsruhe GbmH, October 4, 1983.

[83] H.E. Barner, C.L. Mantell, "Kinetics of Hydrogen Reduction of Manganese Dioxide," I\&EC Process Design and Development, Vol. 7, No. 2, April 1968, pp 285-294.

[84] W.K. Jozwiak, E. Kaczmarek, T.P. Maniecki, W. Ignaczak, W. Maniukiewicz, "Reduction behavior of iron oxides in hydrogen and carbon monoxide atmospheres," Applied Catalysis A: General, Vol 326, 2007, pp 17-27.

[85] U.S. Patent 4,082,834, "Process for Gettering Moisture and Reactive Gases," L.N. Grossman, D.R. Packard, General Electric Company, April 4, 1978.

[86] H. Ohashi, S.R. Sherman, "Analytical Study on Tritium Migration in NGNP and Countermeasures to Reduce Tritium Contamination," submitted for publication in Journal of Nuclear Science and Technology (Japan), December 2007. 
[87] See "Fact Sheet on Tritium, Radiation Protection Limits, and Drinking Water Standards" by the U.S. NRC, http://www.nrc.gov/reading-rm/doc-collections/fact-sheets/tritiumradiation-fs.html.

[88] K. Kizu, T. Tanabe, "Deuterium permeation through metals under hydrogen counter flow," Journal of Nuclear Materials, Vols 266-269, 1999, pp 561-565.

[89] K. Kizu, T. Tanabe, "Counter-diffusion and counter-permeation of deuterium and hydrogen through palladium,” Vols 258-263, 1998, pp 1133-1137.

[90] M.B. Richards, A.S. Shenoy, L.C. Brown, R.T. Buckingham, E.A. Harvego, K.L. Peddicord, S.M. Reza, J.P. Coupey, H2-MHR Pre-Conceptual Design Report: SI Based Plant, GA-A25401, General Atomics Company, April 2006. 